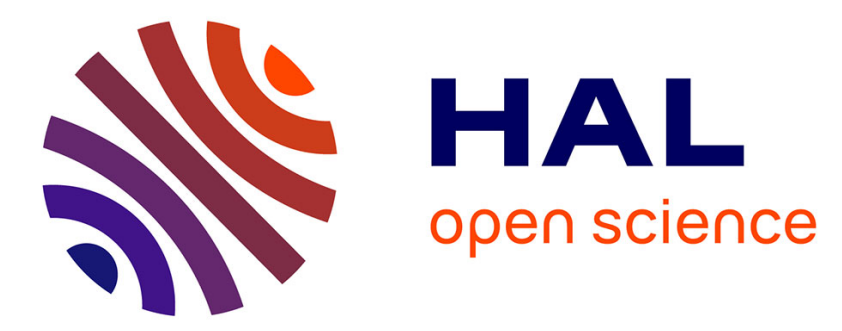

\title{
Un pasteur français au service des Provinces-Unies. Le ministère de Samuel Des Marets à Maastricht (1632-1636) \\ Julien Léonard
}

\section{- To cite this version:}

Julien Léonard. Un pasteur français au service des Provinces-Unies. Le ministère de Samuel Des Marets à Maastricht (1632-1636). Revue d'Histoire Moderne et Contemporaine, 2018, 65-2 (2), pp.97130. 10.3917/rhmc.652.0097 . hal-01872059

\section{HAL Id: hal-01872059 \\ https://hal.univ-lorraine.fr/hal-01872059}

Submitted on 24 Oct 2020

HAL is a multi-disciplinary open access archive for the deposit and dissemination of scientific research documents, whether they are published or not. The documents may come from teaching and research institutions in France or abroad, or from public or private research centers.
L'archive ouverte pluridisciplinaire HAL, est destinée au dépôt et à la diffusion de documents scientifiques de niveau recherche, publiés ou non, émanant des établissements d'enseignement et de recherche français ou étrangers, des laboratoires publics ou privés. 
UN PASTEUR FRANÇAIS AU SERVICE DES PROVINCES-UNIES. LE MINISTĖRE DE SAMUEL DES MARETS À MAASTRICHT (1632-1636)

Julien Léonard

\section{Belin | « Revue d'histoire moderne \& contemporaine »}

2018/2 n 65-2 | pages 97 à 130

ISSN 0048-8003

ISBN 9782410013986

Article disponible en ligne à l'adresse :

https://www.cairn.info/revue-d-histoire-moderne-etcontemporaine-2018-2-page-97.htm

\section{Pour citer cet article :}

Julien Léonard, «Un pasteur français au service des Provinces-Unies. Le ministère de Samuel Des Marets à Maastricht (1632-1636) », Revue d'histoire moderne \& contemporaine 2018/2 ( $\left.\mathrm{n}^{\circ} 65-2\right)$, p. 97-130.

DOI 10.3917/rhmc.652.0097

Distribution électronique Cairn.info pour Belin.

(C) Belin. Tous droits réservés pour tous pays.

La reproduction ou représentation de cet article, notamment par photocopie, n'est autorisée que dans les limites des conditions générales d'utilisation du site ou, le cas échéant, des conditions générales de la licence souscrite par votre établissement. Toute autre reproduction ou représentation, en tout ou partie, sous quelque forme et de quelque manière que ce soit, est interdite sauf accord préalable et écrit de l'éditeur, en dehors des cas prévus par la législation en vigueur en France. Il est précisé que son stockage dans une base de données est également interdit. 


\section{Un pasteur français au service des Provinces-Unies Le ministère de Samuel Des Marets à Maastricht $(1632-1636)$}

Julien LÉONARD ${ }^{1}$

L'étude des pasteurs réformés de l'aire francophone au XVII ${ }^{\mathrm{e}}$ siècle s'est surtout concentrée sur le territoire et la période relevant du régime de l'édit de Nantes (1598-1685), qui assure aux ministres une situation relativement stable (et donc documentée), malgré les remises en cause ${ }^{2}$. L'histoire de ceux qui exercent dans les pays étrangers, où se trouvent également des Églises francophones (Angleterre, Suisse, Saint-Empire, Provinces-Unies notamment) est également plutôt connue, bien que de façon plus éclatée. Ce sont surtout les ministres ayant émigré en masse à partir des années 1680, et principalement après la révocation de l'édit de Nantes, qui ont attiré l'attention. Ils ont produit des documents assez nombreux, édités au XIX ${ }^{\mathrm{e}}$ siècle, et suscité des études d'historiens, comme celle de Hans Bots sur les pasteurs installés aux Provinces-Unies, qui fait encore référence ${ }^{3}$. Pourtant, il existe des ministres nés sujets du roi de France et qui exercent dans des Églises particulières n’appartenant pas aux structures synodales françaises ${ }^{4}$, ou qui prêchent

1. Cette recherche a été financée par l'ANR, pour le projet «LODOCAT - Chrétientés lotharingiennes - Dorsale catholique, $\mathrm{IX}^{\mathrm{e}}$-XVIII ${ }^{\mathrm{e}}$ siècle». Elle a été présentée dans ses grandes lignes le 20 février 2017 au séminaire de l'Institut d'histoire de la Réformation (IHR) à Genève. Les participants de ce séminaire, par leurs remarques constructives, ont considérablement amélioré la qualité de cet article, notamment Nicolas Fornerod, Geneviève Gross, Christian Grosse, Maria-Cristina Pitassi et Daniela Solfaroli Camillocci. Willem Frijhoff m’a également proposé des pistes stimulantes dans la phase finale de rédaction. Je remercie enfin Andreas Nijenhuis-Bescher pour la qualité de ses cartes, ses conseils et ses précisions de spécialiste des Provinces-Unies.

2. Une synthèse: Mark GREENGRASS, "The French pastorate: Confessional identity and confessionalization in the Huguenot minority, 1559-1685", in Luise SCHORN-SCHÜTTE, C. Scott DIXON (éd.), The Protestant Clergy of Early-Modern Europe, Basingstoke, Palgrave Macmillan, 2003, p. 176-195.

3. Hans Bots, «Les pasteurs français au Refuge des Provinces-Unies: un groupe socio-professionnel tout particulier, 1680-1710", in Jens HÄSELER, Antony MCKENNA (éd.), La vie intellectuelle aux Refuges protestants, Paris, Champion, 1999, p. 9-68. Voir une autre liste dans Ferdinand-Henri GAGNEBIN, "Liste des Églises wallonnes des Pays-Bas et des pasteurs qui les ont desservies", Bulletin de la Commission pour l'histoire des Églises wallonnes, 3, 1888, p. 25-63 et p. 97-120.

4. Voir par exemple Julien LÉONARD, Être pasteur au $X V I I^{e}$ siècle. Le ministère de Paul Ferry à Metz (1612-1669), Rennes, Presses universitaires de Rennes, 2015. 
dans des communautés situées à l'étranger, dès le XVI ${ }^{\mathrm{e}}$ siècle, y compris à des périodes où le protestantisme bénéficie dans le royaume d'un régime légal de coexistence.

Peut-être la rareté des cas (relative d'ailleurs, mais cela reste à établir par une enquête plus approfondie) et l'illusion d'un régime juridique protecteur ont-elles masqué ces réalités. Pourtant, malgré les discours loyalistes majoritaires au sein du corps pastoral français ${ }^{5}$, a fortiori après 1629 et l'édit de Nîmes ${ }^{6}$, des prédicateurs réformés français ont été amenés à quitter le royaume et à exercer dans des territoires soumis à une autre souveraineté, notamment au sein des Églises dites "wallonnes». Ces dernières ne sont pas totalement inconnues, surtout dans les historiographies belge et néerlandaise, et elles ont même parfois été étudiées dans leurs rapports avec la France: dans les années 1960 et 1980, les travaux de P. Dibon ou de G. Posthumus Meyjes ont ainsi apporté plusieurs éléments sur les relations entre Églises de France et Églises de réfugiés, sans d'ailleurs éviter certains écueils - voir par exemple dans ces Églises francophones des éléments "précurseurs» de celles de la fin du XVII ${ }^{\mathrm{e}}$ siècle ${ }^{7}$. Mais c'est de toute façon fort peu à côté des très nombreux travaux sur le Refuge huguenot de la période de la Révocation, et même certaines publications donnant l'impression d'englober le début du XVII ${ }^{\mathrm{e}}$ siècle ne le font pas $^{8}$. Les apports récents de l'historiographie, qui peuvent inclure des aspects transnationaux dans l'histoire des relations ecclésiastiques au sein du monde réformé francophone européen ${ }^{9}$, ou qui insistent sur le rôle des réseaux marchands et pastoraux à la même échelle ${ }^{10}$, permettent désormais de nouvelles perspectives.

5. Élisabeth LABROUSSE, "La doctrine politique des huguenots, 1630-1685», Études théologiques et religieuses, 47-4, 1972, p. 421-429; Hubert BosT, "Théories et pratiques politiques des protestants français de la Réforme à la Révolution", Anglophonia, French Fournal of English Studies, 17, 2005, p. 13-24.

6. Philippe Chareyre, "Trente ans après: de la paix à la grâce, l'édit de Nîmes, juillet 1629", in Paul Mironneau, Isabelle PÉBAy-Clottes (éd.), Paix des armes, paix des âmes, Paris, Imprimerie nationale, 2000, p. 343-370; Jean HuBAC, La paix d'Alès. La fin du parti huguenot? (27 juin 1629), Paris, Éditions de Paris - Max Chaleil, 2010.

7. Paul DiBon, "Le Refuge wallon, précurseur du Refuge huguenot», Dix-septième siècle, 76-77, 1967, p. 53-74; Guillaume Henri Marie POSTHUMUS MEYJES, "Les rapports entre les Églises wallonnes des Pays-Bas et la France avant la Révocation ", in H. Bots, G.H.M. Posthumus Meyjes (éd.), La révocation de l'édit de Nantes et les Provinces-Unies, 1685, Amsterdam et Maarssen, APA-Holland University Press, 1986, p. 1-15.

8. Parmi de nombreux exemples possibles, je préfère citer un volume qui est par ailleurs en tous points remarquable et qui, malgré les bornes chronologiques de son titre, passe très superficiellement sur les manifestations précoces du Refuge: Chrystel BERNAT, Eckart BIRNSTIEL (éd.), La diaspora des huguenots. Les réfugiés et leur dispersion dans le monde (XVI -XVIII siècle), Paris, Champion, 2001.

9. Voir en dernier lieu et sur une période beaucoup plus tardive: Pauline DULEY-HAOUR, Désert et Refuge: sociohistoire d'une internationale huguenote. Un réseau de soutien aux "Églises sous la croix» (1715-1752), Paris, Champion, 2017.

10. Un point et des renvois bibliographiques par Ole Peter GRELL, «The creation of a transnational, Calvinist network and its significance for Calvinist identity and interaction in early modern Europe", European Review of History - Revue européenne d'histoire, 16-5, 2009, p. 619-636. 
Dans ce domaine, il existe un véritable problème des sources à propos de la guerre de Trente Ans, dont le rapport à la religion reste un sujet de débat ${ }^{11}$. C'est pourtant au cœur de ce long conflit qui interroge leurs pratiques et au sein de territoires sous domination néerlandaise que l'on peut observer l'attitude de certains pasteurs francophones, et en particulier d'individus nés et formés dans le royaume de France. Déconnectant d'une certaine manière identité confessionnelle et identité politique dans un contexte étranger de protection par le pouvoir politique (et non pas de simple tolérance comme en France), ils proposent une vision particulière de leur propre vocation et de leur ministère. On peut donc se demander ce qu'ils conservent de modèles français et ce qu'ils apportent de nouveau, soit de modèles nationaux (néerlandais surtout), soit de modèles plus marginaux (autour d'expériences périphériques comme celle de la principauté de Sedan). Bien entendu, il faut conserver à l'esprit que les contextes locaux peuvent être déterminants et très fluctuants par rapport à ces modèles, forgés à d'autres échelles et mieux connus par les sources normatives.

Cet article propose quelques pistes de réflexion à partir d'un cas très précis, mais relativement bien documenté, celui de Samuel Des Marets (1599-1673) à Maastricht, entre fin 1632 et début 1636. Malgré la brièveté de la période et la grande singularité de l'exemple, tant par le personnage principal que par le théâtre de son action, au contact de la «Dorsale catholique» qu'avait définie René Taveneaux ${ }^{12}$, quelques réponses émergent sur les identités politique et confessionnelle de ce pasteur, un sujet de Louis XIII passé au service du duc de Bouillon et des États-Généraux des Provinces-Unies, fort actif dans la lutte contre les catholiques, mais visiblement encore très marqué culturellement par ses premiers pas de pasteur français.

\section{Samuel Des Marets, UN PASTEUR FRANÇAIS S'ÉLOIGNANT DES INSTITUTIONS SYNODALES}

Samuel Des Marets est l'un de ces pasteurs brillants et célèbres dès leur jeunesse, formés au cours des premières années du régime de l'édit de Nantes. Bien que l'essentiel de notre connaissance sur le début de son ministère nous

11. Voir ces dernières années Cornel ZwIERLEIN, "The Thirty Years' War - A religious war? Religion and machiavellism at the turning point of 1635 ", in Olaf ASBACH, Peter SCHRÖDER (éd.), The Ashgate research Companion to the Thirty Years' War, Farnham, Ashgate, 2014, p. 231-243; Bertrand ForClaz, Philippe MARTin (éd.), Religion et piété au défi de la guerre de Trente Ans, Rennes, Presses universitaires de Rennes, 2015.

12. René TAVENEAUX, «Réforme catholique et Contre-Réforme en Lorraine», in ID., fansénisme et Réforme catholique, recueil d'articles, Nancy, Presses universitaires de Nancy, 1992, p. 5-15. Sur le concept, en attendant la publication de tous les travaux de l'ANR "LODOCAT»: Frédéric MEYER, "La Dorsale catholique, XVI ${ }^{\mathrm{e}}$-XVIII ${ }^{\mathrm{e}}$ siècle: mythe, réalité, actualité historiographique», in Gilles DEREGNAUCOURT et alii (éd.), Dorsale catholique, jansénisme, dévotions: XVIe-XVIII siècle. Mythe, réalité, actualité historiographique, Paris, Riveneuve, 2014, p. 319-330. 
vienne d'une source qu'il a lui-même contrôlée dans sa vieillesse de professeur de théologie à Groningue ${ }^{13}$, ensuite reprise par la plupart des notices biographiques ${ }^{14}$, on y perçoit l'univers social et culturel dans lequel il a baigné avant d'arriver aux Provinces-Unies. Il naît le 9 août 1599 à Oisemont, en Picardie, dans une famille très ordinaire pour un pasteur, relativement aisée et engagée depuis deux générations déjà dans la vie des Églises réformées. Il est toutefois le premier de son entourage à embrasser cette carrière. Sa formation pastorale est classique et académique. Ses parents ont les moyens de financer des études universitaires, et son frère Charles choisit pour sa part la voie du barreau qui le fait passer à Heidelberg et Orléans. Le jeune Samuel, quant à lui, est d'abord envoyé à Paris, dès l'âge de treize ans, pour faire sa philosophie, puis il se dirige en 1615 vers Saumur où il suit les cours de Louis Cappel (1585-1658) en hébreu, mais aussi et surtout de François Gomar (1563-1641) en théologie. Ce défenseur obstiné de l'orthodoxie calviniste formulée par Théodore de Bèze joue sans doute un rôle considérable dans le positionnement dogmatique de Des Marets et, même si les sources sont discrètes sur ce fait, c'est au départ de Gomar pour Groningue, et peut-être à cause de l'arrivée de théologiens moins clairement "orthodoxes", que le jeune homme quitte les rives de la Loire pour celles du lac Léman. À Genève, où il est immatriculé en théologie le 29 août $1618^{15}$, il suit les cours d'autres figures de proue de l'orthodoxie, notamment Théodore Tronchin (1582-1657), Giovanni Diodati (1576-1649) et Bénédict Turrettini (1588-1631), en un moment crucial, celui du synode de Dordrecht, auquel Diodati et Tronchin participent et qui fixe les contours du calvinisme "officiel»" 16 .

Ce qui est peut-être plus original dans la formation de Des Marets (en tout cas, il est original que nous le sachions), c'est qu'elle est également en partie "pratique». Les universités et académies de l'Europe réformée préparent des théologiens relativement érudits, mais on sait fort peu de choses sur la transmission des aspects plus concrets du métier de pasteur, même si, à Genève par exemple, les proposants (de jeunes théologiens en attente de

13. Effigies \& vitce professorum Academice Groninge \& Omlandice, Groningue, Nicolai, 1654, p. $134-153$

14. Notamment, en français: Pierre BAYLE, Dictionnaire historique et critique, Rotterdam, Leers, 1697, vol. 2, p. 554-561; Jean-Pierre NICERON, Mémoires pour servir à l'histoire des hommes illustres dans la République des Lettres, Paris, Briasson, 1727-1745, vol. 28 (1734), p. 46-91; Jean-Noël PAQUOT, Mémoires pour servir à l'histoire littéraire des dix-sept provinces des Pays-Bas, de la principauté de Liège, et de quelques contrées voisines, Louvain, Imprimerie académique, 1763-1770, vol. 3 (1764), p. 216-251; Eugène et Émile HAAG, La France protestante, Paris, Cherbuliez, 1846-1859, vol. 4 (1853), p. 249-257 - notice légèrement remaniée dans la 2e éd., éd. Henri-Léonard BoRDIER, Paris, Sandoz et Fischbacher, 1877-1888, vol. 5 (1886), col. 320-332. Pour une vision plus complète (en néerlandais) : Doede NAUTA, Samuel Maresius, Amsterdam, Paris, 1935.

15. Sven Stelling-Michaud (éd.), Le livre du recteur de l'académie de Genève (1559-1878), Genève, Droz, 1959-1980, vol. 1 (1959), p. 159, n² 376, et vol. 3 (1972), p. 96-97.

16. Nicolas FORNEROD, "“The canons of the Synod had shot off the advocate's head": A reappraisal of the Genevan delegation at the Synod of Dordt", in Aza GoUdRIAAN, Fred VAN LiEburG (éd.), Revisiting the Synod of Dordt (1618-1619), Leyde, Brill, 2011, p. 181-215. 
confirmation pastorale) prêchent à la campagne et siègent comme observateurs dans certaines institutions ecclésiastiques ${ }^{17}$. De part et d'autre de sa période d'études, Des Marets se place sous la protection d'un pasteur et apprend avec lui comment exercer ce métier, d'abord à Oisemont avec Ésaïe Blanchard, puis surtout à Paris et Charenton en 1619-1620 avec Samuel Durant (1574-1626) qui lui enseigne comment prêcher et placer sa voix, mais aussi comment exercer la discipline, ce qui est une des missions attendues du pasteur. Peut-être est-ce là aussi qu'il prend conscience des enjeux de la controverse contre les catholiques, quotidienne dans la plupart des Églises de France, surtout au nord du royaume, dans un contexte d'ultra-minorité. Il se prépare ainsi à l'étape suivante: se présenter devant un synode provincial ou un colloque pour être examiné sur ses mœurs (par des attestations) et surtout sur sa doctrine (par des propositions devant au moins sept pasteurs), avant d'être envoyé devant son Église pour trois semaines et enfin de recevoir l'imposition des mains. Le synode provincial d'Île-de-France le déclare apte en 1620 et l'envoie à Laon, dans le colloque de Picardie. Victime d'une sombre histoire d'attentat qui met peut-être en cause le jésuite Aubigny, le confesseur de Ravaillac, il passe quelques mois à Paris, puis est appelé par le synode provincial de Vitry à Falaise, dans le colloque de Champagne, en 1624.

Sa carrière bascule vite car il prend une voie qui cesse d'être ordinaire pour un pasteur des Églises réformées de France. Il est en effet appelé en 16241625 à remplacer à Sedan Jacques Cappel du Tilloy (1570-1624) à la chaire de théologie de l'académie, dans une principauté souveraine et indépendante de la France. C'est cette situation institutionnelle particulière qui a déjà permis à Sedan de jouer en 1621-1622 le rôle de refuge pour le célèbre pasteur parisien Pierre Du Moulin (1568-1658), qui vient y achever sa longue carrière. Des Marets voyage d'abord en Hollande et en Angleterre. Il est immatriculé le 19 juin 1625 à Leyde et devient docteur le 8 juillet ${ }^{18}$, avant d'enfin commencer à exercer à Sedan à partir de novembre. Il connaît toutefois quelques ennuis disciplinaires et personnels. En effet, il s'entend mal avec des figures imposantes comme Du Moulin qui lui «procur[e] tous les petits desplaisirs dont il se peut adviser ${ }^{19}$. Surtout, il est suspendu de son ministère dès le 17 avril 1625 par le synode provincial d'Île-de-France pour avoir rallié Sedan sans congé, et bénéficie alors de la protection d'Élisabeth de Nassau (15771642), régente de la principauté depuis la mort de son mari Henri de La Tour d'Auvergne (1555-1623). Elle a déjà travaillé à la vocation de Des Marets et rappelle en son conseil le 8 mai 1625 que les Églises de la souveraineté

17. Karin MAAG, Seminary or University? The Genevan Academy and Reformed Higher Education, 1560-1620, Aldershot, Scolar, 1995.

18. Philip Christiaan MoLHUYSEN (éd.), Bronnen tot de geschiedenis der Leidsche universiteit 1574-1811, La Haye, Nijhoff, 1913-1924, vol. 2 (1916), p. 120 (thèse De justificatione hominis coram Deo).

19. Bibliothèque universitaire (désormais BU) de Leyde, BPL 297, $\mathrm{f}^{\circ} 1-2$, lettre de Des Marets à André Rivet, écrite du camp de Waalwijk, le 22 août 1631. 
de Sedan ne dépendent pas de la juridiction disciplinaire des synodes français ${ }^{20}$, ce qui est d'ailleurs en rupture avec des pratiques précédentes.

À Sedan, même s'il se marie en mai 1628 avec Abigaïl Legrand, réfugiée d'Aix-la-Chapelle et veuve de Jean Boots, sans doute un Néerlandais, la situation du pasteur ne semble pas se stabiliser, comme le note Pierre Bayle: «Il eut à essuyer quelques bourasques, contre lesquelles il se soutint fermement par la faveur du duc de Bouillon, \& par l'affection de l'Église " ${ }^{21}$. À vrai dire, c'est surtout Élisabeth de Nassau, fille de Guillaume le Taciturne et mère du jeune duc de Bouillon, qui favorise la carrière de Des Marets. C'est à elle qu'il adresse une épître dédicatoire très déférente dans son premier ouvrage, en 1628:

"Vous seule, Madame, m'avez fait ce que je suis en cest Estat, m'y ayant honorablement appellé de la solitude champestre \& lors que je pensois le moins à une telle faveur pour servir en l'Église \& en l'Academie tout ensemble, \& selon quelques pensées que V. E. m'a dit feu Monseigneur en avoir eu si l'occasion s'en fust presentée de son vivant: En diverses occasions par lesquelles il a pleu à Dieu de m'exercer j'ay tousjours eu mon recours à vostre juste protection comme à un refuge asseuré: Vostre recommandation m'a donné très bonne part ès bonnes graces de Monseigneur, nostre Prince, que la pieté, la prudence, la vaillance, la debonnaireté rendent aujourd'huy les delices du peuple Hollandois comme Tite le fut autresfois du Romain; \& la bienveillance qu'il a pleu à V. E. de me tesmoigner l'affection commune de toute sa très illustre Maison $»^{22}$.

C'est bien à cette "très illustre Maison" (document 1) qu'il est désormais attaché. Le jeune prince, Frédéric-Maurice (1605-1652), duc de Bouillon, est alors aux Provinces-Unies en formation auprès de ses oncles, les stathouders et princes d'Orange Maurice (1567-1625), puis Frédéric-Henri (1584-1647)23. Il participe ainsi à la guerre contre l'Espagne, notamment aux sièges de Breda (1624-1625) et de Bois-le-Duc (1629). Malgré la défaite lors du premier, le second permet d'étendre le territoire sous domination des États-Généraux et pose la question de la calvinisation, même si elle aboutit à un échec global dans le Brabant (document 2).

La protection de la famille princière de Sedan amène la carrière pastorale de Des Marets à connaître une dernière évolution rapide. Il arrive en 1631 aux Provinces-Unies, dans le sillage des troupes que Frédéric-Henri a confiées à Frédéric-Maurice. Il sert de pasteur de l'Église domestique de ce dernier et d'aumônier auprès des soldats durant les campagnes de 1631, avec

20. L'affaire est exposée en détail dans une longue lettre postérieure de Des Marets à Rivet (BU Leyde, BPL 297, f $79-85,23$ mai 1643). Voir aussi la présentation "à chaud" dans le registre du consistoire de Sedan, lors de la séance du 15 mai 1625, archives départementales des Ardennes (désormais AD 08), 31J 4, f $185 \mathrm{r}$. Je remercie Éric Montat, directeur des archives départementales des Ardennes, pour son aide.

21. P. BAYLE, Dictionnaire..., op. cit., vol. 2, p. 556.

22. Samuel Des MARETS, Preservatif contre la revolte, Sedan, Jannon, 1628, n.p.

23. Sur le lien entre les familles de Bouillon et d'Orange, voir, à travers un cas plus célèbre, Willem FRIJHOFF, "L'image de Turenne aux Pays-Bas depuis la guerre de Hollande", in Laurent JALABERT, Cédric Moulis (éd.), "Nouveaux regards sur Turenne", numéro spécial des Annales de l'Est, 2011, p. 225-249, notamment p. 226-231. 


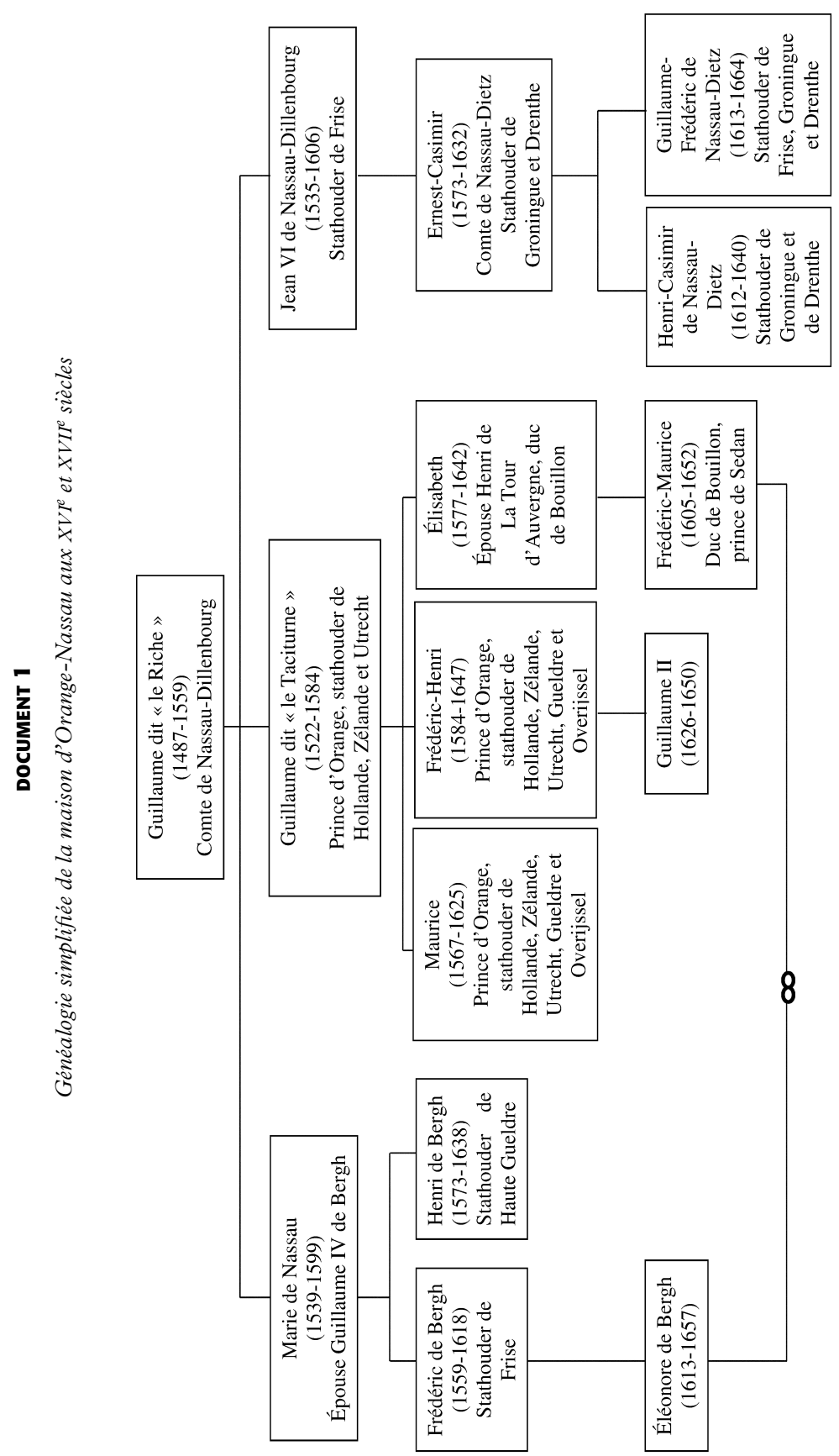




\section{DOCUMENT 2}

Situation confessionnelle des Provinces-Unies vers 1650 (estimation à partir d'une extrapolation fondée sur un recensement de l'époque française)

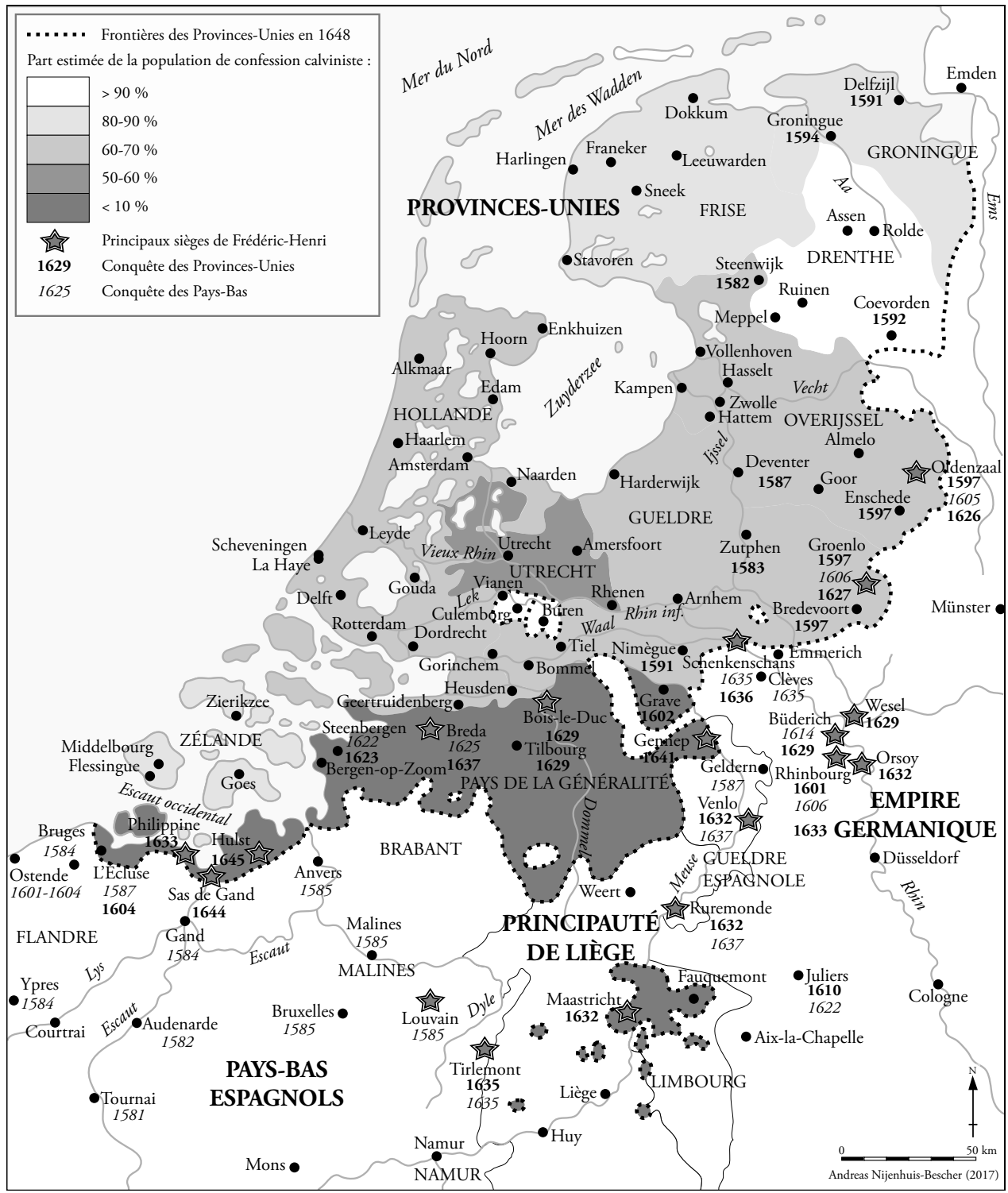


l'autorisation de l'Église de Sedan qui lui donne son congé ${ }^{24}$. Revenu brièvement à Sedan, il repart dès 1632, d'abord avec la régente Élisabeth de Nassau. Un événement militaire le fixe auprès d'une nouvelle conquête majeure des Provinces-Unies: Maastricht. Avec Sedan, il s'agit d'un autre point de contact essentiel - presque missionnaire - entre un monde catholique de combat au sein de la "Dorsale catholique» et des poches d'expansion du calvinisme, mais un calvinisme qui n'est plus dans l'orbite des institutions ecclésiastiques françaises régies par l'édit de Nantes, et qui, de ce fait, prend un véritable aspect particulariste, favorisant l'émergence de modèles ecclésiastiques originaux.

\section{MAASTRICHT, UN TERRAIN PARTICULIER POUR LES CONTROVERSES CONFESSIONNELLES}

Dans le cadre de ses menées pour contrôler la Meuse suite à la prise de Boisle-Duc, le stathouder Frédéric-Henri, avec le soutien des États-Généraux, souverains des Provinces-Unies, met le siège devant Maastricht le 10 juin 1632. Il est donc accompagné par son neveu, le duc de Bouillon, qui joue un rôle actif. Les enjeux stratégiques et géopolitiques sont évidents pour cette place qui contrôle un passage du fleuve (document 3). La ville est, de plus, chargée d'une forte dimension mémorielle, car elle avait été prise par les Espagnols en 1579 , donnant lieu à une violente éradication du protestantisme. Cela explique sans doute pourquoi le siège, bien que relativement court (il dure jusqu'au 22 août 1632), donne lieu à une intense ferveur calviniste, avec l'organisation de journées de jeûne et d'actions de grâce, notamment les 24 et 25 août $^{25}$, y compris dans les Églises de langue française établies sur le territoire néerlandais. On le voit dans un recueil de sermons sur ce sujet prononcés par le célèbre André Rivet (1573-1651), installé en Hollande depuis 1621 et très proche de la famille d'Orange-Nassau ${ }^{26}$.

Il s'agit d'une incursion des troupes néerlandaises au cœur des Pays-Bas espagnols et de leur frontière avec la principauté de Liège, à proximité de Sedan et du duché de Bouillon. Le sort de la religion réformée dans les territoires conquis par le prince d'Orange est assez précocement pris en compte et, par exemple, le catholicisme est rudement traité à Bois-le-Duc en 162927. Toutefois, au printemps 1632, préparant les campagnes militaires, une déclaration des États-Généraux prévoit de conserver les places conquises sur les Espagnols

24. AD 08, 31J 4, f ${ }^{\circ}$ 191v, registre du consistoire de Sedan, séance du 15 mai 1631.

25. Albert Waddington, La République des Provinces-Unies, la France \& les Pays-Bas espagnols de 1630 à 1650, Paris, Masson, 1895-1897, vol. 1 (1895), p. 145.

26. André RIVET, Exhortations à repentance et recognoissance: Faites au subjet du siege, $\mathcal{E}$ de la reddition de Maestricht, l'onzieme $\mathfrak{E} X X I V$. Aoust, en l'Eglise Françoise de La Haye, Leyde, Elzevier, 1632.

27. Sur les liens entre armée et confessionnalisation: Andreas NIJENHUIS-BESCHER, "On a laissé quelques Couvens de Religieuses, mais chassé tous les gens de l'église": la "Milice" des ProvincesUnies sous Frédéric-Henri d'Orange (1584-1647), bras armé d'un État confessionnel", in L. JALABERT, Stefano SimIZ (éd.), Le soldat face au clerc. Armée et religion en Europe occidentale (XVe-XIXe siècle), Rennes, Presses universitaires de Rennes, 2016, p. 245-268, p. 261-262 sur le cas de Bois-le-Duc. 


\section{DOCUMENT 3}

Situation géopolitique régionale autour de Maastricht après le siège de 1632

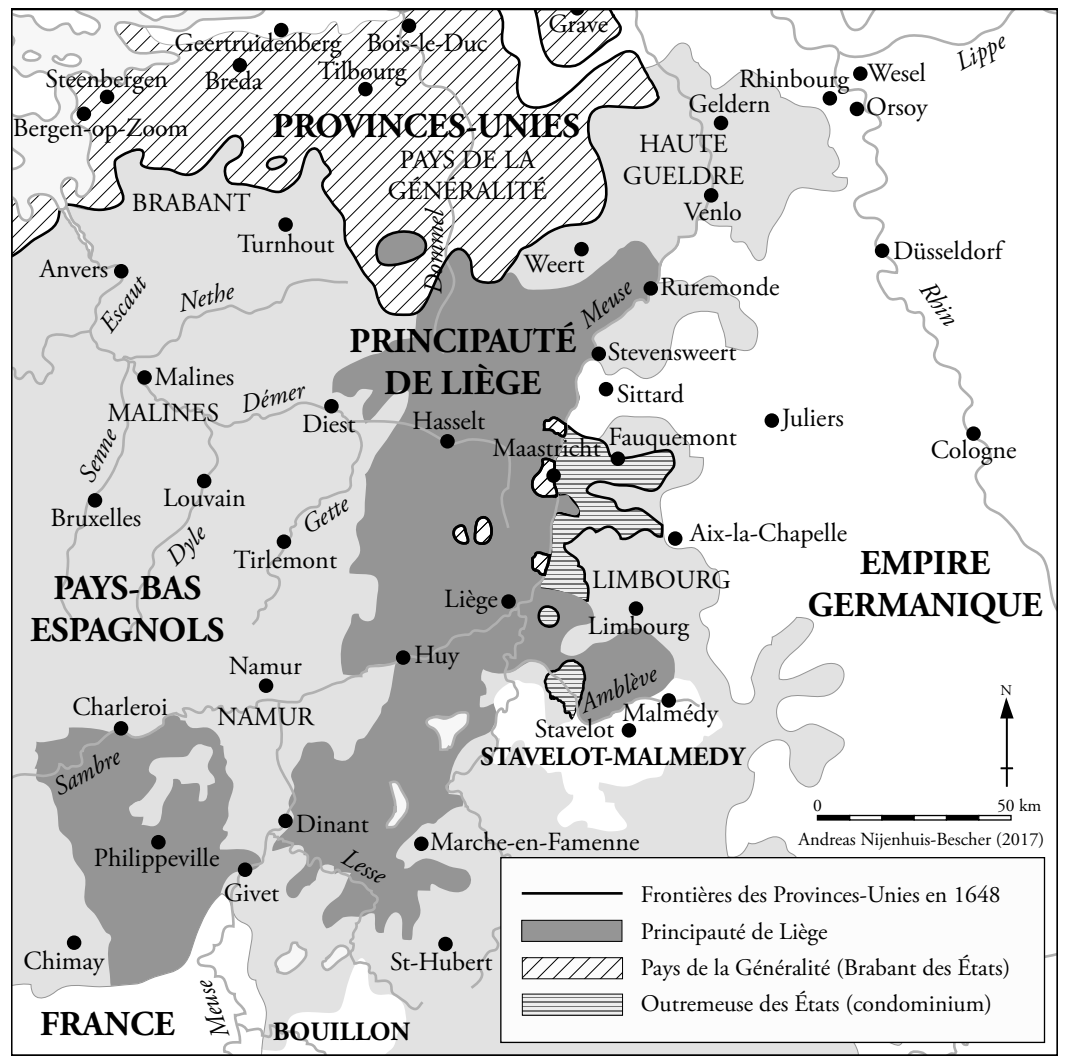

dans leurs privilèges et d'y maintenir le catholicisme ${ }^{28}$, facilitant le passage dans le camp des Provinces-Unies de Henri de Bergh, stathouder catholique de la Haute Gueldre, espagnole. À Maastricht, la prudence doit être redoublée. En effet, la ville ne tombe pas sous le contrôle des seuls Néerlandais: un régime de condominium très ancien y prévoit la co-souveraineté des ducs de Brabant (c'est-à-dire, depuis le XVI ${ }^{\mathrm{e}}$ siècle, des rois d'Espagne) et des princes-évêques de Liège ${ }^{29}$. Les États-Généraux veillent à ce que la prise de la ville ne remette pas en cause ces équilibres, et surtout la neutralité liégeoise, peut-être sous la

28. Declarations des Estats Generaux des Provinces Unies du Pays-Bas, aux Provinces $\&$ Villes, du Pays bas subject au Roy d'Espaigne, du 22. de May, E de l'onsiesme de septembre 1632, La Haye, Veuve \& Héritiers de Hillerbrant Jacobffz de Wouw, 1632.

29. Petrus Joseph Hubertus UBACHS, Twee heren, twee confessies. De verhouding van Staat en Kerk te Maastricht, 1632-1673, Assen, Van Gorcum, 1975. Voir également A. NiJENHUIS-BESCHER, "On a laissé..."”, art. cit., p. 264-266. 
surveillance de la France, alliée encore discrète des Provinces-Unies et intéressée à maintenir de bonnes relations avec la principauté ${ }^{30}$. Dans la capitulation signée par Frédéric-Henri le 22 août 1632, la situation est claire (art. 6-7):

"Que les Seigneurs Estats des Provinces unies ne pourront entreprendre dans lad. Ville, et le District d'Icelle, autre chose que ce qui a appartenu au Roy d'Espagne, comme Duc de Brabant [...].

Que lesd. Seigneurs Estats gouverneront conjointement avec led. Evesque et Prince de Liege lad. Ville, comme un estat et Province particuliere separée des autres Estats ou Provinces desdits deux Seigneurs, de meme que l'evesque et le Roÿ d'Espagne ont gouverné lad. Ville ${ }^{31}$.

Mais, et c'est révélateur, le stathouder s'est déjà préoccupé avant cela de l'établissement d'un culte réformé (art. 2) : "Que doresnavant la Religion Reformée se pourra exercer librement et publicquement en lad. Ville de Maestricht de la meme manière, qu'elle s'exerce dans les Provinces unies ${ }^{32}$. Cet article est modéré par le suivant, qui garantit les biens et privilèges du clergé, et établit la reconnaissance publique de la majorité catholique (art. 4): «En suitte de quoÿ, demeurera dans lad. Ville le libre exercice public de la Religion Catholique Romaine, dans les eglises, cloistres, et par tout ailleurs, de la manière que lad. Religion y a esté exercée jusques à present sans aucun obstacle ou empeschement "33. Les députés de Liège envoyés à La Haye quelques mois plus tard rappellent même "Que la juridiction ecclesiastique et droicts competens en vertu d'icelle à l'Evesque et l'Église de Liege à Maestricht, au pays de Limbourg et autres estans du diocese de Liege [doivent être] entierement maintenus et conservez $»^{34}$.

Au vu de la situation démographique (3 500 protestants, dont de nombreux soldats, sur 16000 habitants $)^{35}$, la situation des calvinistes est privilégiée. Il est décidé de permettre deux cultes, dont un francophone ${ }^{36}$. C'est particulièrement stratégique et potentiellement polémique à proximité du pays de Liège.

30. Voir cet intérêt pour la situation à Maastricht aux archives du ministère des Affaires étrangères, La Courneuve (désormais MAE), CP Hollande, vol. 19, f 193-241 (avec notamment l'annonce de l'envoi d'une carte le 21 juin 1632 durant le siège, $\mathrm{f}^{\circ}$ 194-195). Sur les intérêts français à Liège, voir MAE, CP Liège, vol. 1, fo 77-145. Théodore GOBERT, «Le rôle de la France au Pays de Liège durant le second quart du XVII ${ }^{\mathrm{e}}$ siècle. Récit d'un ambassadeur français de l'époque", Bulletin de l'Institut archéologique liégeois, 41, 1911, p. 1-61; Paul HARSIN, "Esquisse de la politique de la France à l'égard de la principauté de Liège, particulièrement au XVII ${ }^{\mathrm{e}}$ siècle", Revue d'histoire moderne, 2, 1927, p. 99-128; ID., "La neutralité liégeoise en 1632 ", Revue d'histoire moderne, 15, 1940, p. 13-31; Bruno DEMOULIN, "La principauté de Liège. Champ clos des rivalités franco-espagnoles (1595-1648)", Revue du Nord, 90-377, 2008, p. 717-727; B. Demoulin, Jean-Louis KupPER, Histoire de la principauté de Liège: de l'an mille à la Révolution, Toulouse, Privat, 2002.

31. Cité d'après MAE, CP Hollande, vol. 19, f 227-228, Articles accordez par Monsieur le Prince d'Orange aux Ecclesiastiques et Magistrats de la ville de Mastricht.

32. Ibidem.

33. Ibidem.

34. MAE, CP Liège, vol. 1, f० 86-87, 2-5 mars 1633

35. P.J.H. UBACHS, Twee heren..., op. cit., p. 450.

36. Nationaal Archief, La Haye (désormais NA), inv. 1.01.02, vol. 57 (résolutions des ÉtatsGénéraux, 1632), notamment $\mathrm{f}^{\circ} 588$ (11 septembre), $\mathrm{f}^{\circ}$ 610-611 (20 septembre) et $\mathrm{f}^{\circ} 656$ (11 octobre). 
Dès les lendemains de l'annonce de la prise de la ville, Rivet peut exulter en chaire, à La Haye, un des cœurs du pouvoir néerlandais, en évoquant ces «Temples qui nous sont ouverts à présent» avec, au passage, un usage du «nous» qui mériterait sans doute une étude ${ }^{37}$.

À côté de la ville de Maastricht proprement dite se trouvent de part et d'autre de la Meuse des territoires rattachés aux Pays de la Généralité, mais aussi des terres qui sont érigées en 1632 en condominium et unies à Maastricht sous le nom d'Outre-Meuse des États, sans compter l'occupation du duché de Limbourg. Dans des conditions sensibles et volatiles, les États-Généraux se préoccupent concrètement de l'installation des Églises réformées, jusque dans le choix des pasteurs ${ }^{38}$, au risque de contestations disciplinaires sur lesquelles on reviendra ${ }^{39}$. Ces Églises réformées, à la fois néerlandophones et francophones, existent parfois de façon éphémère, dans un milieu dangereux à cause des troupes espagnoles ${ }^{40}$. André Rivet, qui s'occupe alors à La Haye de l'éducation du jeune Guillaume II, l'héritier de Frédéric-Henri, est prioritairement consulté sur le choix des pasteurs dans la partie francophone ${ }^{41}$. Il est sans doute le meilleur exemple de l'interpénétration des réseaux à la fois intellectuels et nobiliaires qui sont alors mobilisés. Son collègue parisien Jean Daillé (1594-1670) lui écrit qu'il «prie Dieu qu'il béni[sse] [son] dessein pour l'établissement de l'Église de Maestricht \& [y] envoier des ouvriers capables d'y travailler dignement ${ }^{42}$. Rivet a-t-il déjà Des Marets en tête? Et avait-il une grande marge de manœuvre, depuis que le gouverneur de Maastricht était le duc de Bouillon, protecteur et employeur du pasteur? Il est possible que l'on ait envisagé dans un premier temps de faire venir de Sedan un ministre plus prestigieux, comme Pierre Du Moulin ou Abraham Rambour (1590-1651), mais il est résolu de prendre le chapelain de la famille princière de Sedan ${ }^{43}$. Des Marets est installé dans la chapelle Saint-Hilaire le 3 octobre 1632 et déchargé de ses fonctions sedanaises le 20 décembre ${ }^{44}$, avec l'assentiment au

37. A. Rivet, Exhortations..., op. cit., p. 143-144.

38. NA, inv. 1.01.02, vol. 57 (résolutions des États-Généraux, 1632), f 588 .

39. Sur ce sujet, mais dans une perspective moins centrée sur Des Marets, J. LÉONARD, «Les États-Généraux ou le synode? Conflits d'autorités autour de l'établissement des pasteurs francophones à Maastricht et dans le Limbourg (1632-1636)", Annales de l'Est, numéro spécial, 2018, à paraître.

40. Charles RAHLENBECK, "Le protestantisme dans les pays de Limbourg et d'Outre-Meuse», Revue trimestrielle, 11, 1856, p. 86-120; Joseph DARIS, Histoire du diocèse et de la principauté de Liège pendant le XVII siècle, Liège, Demarteau, 1877; Gaston DAVENNE, "Notes et documents pour servir à l'histoire des communautés réformées de Verviers, Hodimont, Petit-Rechain et Limbourg de 1632 à 1635 ", Bulletin de l'Institut archéologique liégeois, 68, 1951, p. 39-78; Émile-E. BRAEKMAN, "Les Églises protestantes du Limbourg au XVII ${ }^{\mathrm{e}}$ siècle d'après les actes des synodes wallons", in Philippe DENIS (éd.), Protestantisme aux frontières. La Réforme dans le duché de Limbourg et dans la principauté de Liège (XVI $I^{e}$ XIX $X^{e}$ siècle), Aubel, Gason, 1985, p. 213-234.

41. NA, inv. 1.01.02, vol. 57 (résolutions des États-Généraux, 1632), f 588

42. BU Leyde, BPL 279, f 12,12 octobre 1632.

43. NA, inv. 1.01.02, vol. 57 (résolutions des États-Généraux, 1632), f 591r (13 septembre); D. NAUTA, Samuel Maresius, op. cit., p. 108-109.

44. D. NAUTA, Samuel Maresius, op. cit., p. 103. Les registres du consistoire de Sedan n'en conservent aucune trace. 
moins a posteriori de Rivet, son correspondant tout au long de son ministère à Maastricht ${ }^{45}$, un ministère mouvementé.

\section{Samuel Des Marets, un pasteur de combat}

Des Marets arrive dans un environnement qui peut lui rappeler ses premières années de ministère, lorsqu'il exerçait sous la menace des controversistes catholiques. À Sedan et aux armées du stathouder ou de Frédéric-Maurice, il a sans doute eu bien plus de liberté et n'a pas eu à affronter les catholiques au quotidien, même si c'est dans la principauté qu'il fourbit certaines de ses armes de controversiste, contre le jésuite Regourd, et qu'il rédige son premier ouvrage du genre ${ }^{46}$. Bénéficie-t-il à Maastricht d'une marge de manœuvre plus grande que s'il avait été au service d'une des Églises réformées de France? Dans ces dernières, les conditions de la controverse sont encadrées, et les pasteurs sont invités à ne pas être les agresseurs, sous le contrôle des consistoires et des synodes ${ }^{47}$. À Maastricht, Des Marets n'est pas délivré de toute contrainte, loin de là. Les États-Généraux dont il dépend veillent à ce que la coexistence de deux Églises publiques soit pacifique, conformément aux conditions de la capitulation et pour ménager les autorités liégeoises. De plus, un système synodal existe et tente de contenir les éléments les plus bouillants. Pourtant, Des Marets se comporte à Maastricht de façon assez agressive et propose un modèle pastoral de combat, comme s'il était un missionnaire en terre de conquête, mais un missionnaire finalement coupé de ses bases arrières et contraint à quelques assouplissements.

Les sources biographiques, rédigées sur le tard comme on l'a vu (et donc à prendre avec la plus grande prudence), précisent que le pasteur, qui aurait déjà appris l'italien à Sedan, se serait frotté à l'espagnol ${ }^{48}$ : cette indication souligne surtout que son combat anticatholique se situe dans une dimension anti-espagnole marquée. Cela ne peut que satisfaire les autorités des Provinces-Unies, ainsi que la France, où le parti pro-espagnol, sous le ministériat de Richelieu, est présenté à des fins politiques comme confiné dans le monde des dévots ${ }^{49}$.

45. BU Leyde, BPL 297, f 1-39, correspondance presque intégralement publiée par D. NAUTA, Samuel Maresius, op. cit., p. 434-465 (je ne renvoie qu'aux cotes originales).

46. S. Des Marets, Preservatif..., op. cit.

47. Isaac D'HuisseAu (éd.), La discipline des Églises reformées de France ou L'ordre par lequel elles sont conduites et gouvernées, Genève et Saumur, Desbordes, 1667, p. 79 (chap. 1, art. 15) et p. 245-246 (chap. 6, art. 4). Jacques SolÉ, Les origines intellectuelles de la révocation de l'édit de Nantes, Saint-Étienne, Publications de l'université de Saint-Étienne, 1997; Didier BoISSON, "Les pasteurs du XVII siècle et la controverse religieuse", Bulletin de la Société de l'histoire du protestantisme français, 156-1, 2010, p. 69-80.

48. Voir sur ce sujet J.-P. NICERON, Mémoires..., op. cit., p. 53, mais les Effigies..., op. cit., n'en parlent pas.

49. Pour une présentation nuancée, contextualisée et renvoyant à la bibliographie récente sur la question: Serge BRUNET, «Une religiosité influencée par l'Espagne chez les ligueurs puis dévots? Position du problème", in ID. (éd.), La Sainte Union des catholiques de France et la fin des guerres de Religion (1585-1629), Paris, Classiques Garnier, 2016, p. 421-457. 
De ce point de vue, le caractère combatif de Des Marets peut ne pas heurter son identité de protestant français, tout en se mettant au service de l'expansion d'un calvinisme sous protection néerlandaise.

Le pasteur trouve des adversaires à sa hauteur. Il s'agit principalement des jésuites de Maastricht, présents dans la ville depuis 1574 grâce à leur collège (avec une interruption due à la guerre entre 1578 et 1580$)^{50}$. Mais Des Marets s'attaque aussi et surtout à ceux qu'il considère comme les véritables meneurs du catholicisme du lieu, c'est-à-dire les dirigeants de la principauté de Liège. C'est que cette dernière est un État ecclésiastique de facto (même si Des Marets le conteste du point de vue juridique dans certains de ses ouvrages ${ }^{51}$ ), dirigé en théorie par Ferdinand de Bavière. Il est prince-évêque depuis 1612, réellement engagé dans la Réforme catholique mais trop occupé par ses autres (nombreux) bénéfices, notamment l'archevêché-électorat de Cologne, pris dans la mécanique des alliances au cours de la guerre de Trente Ans (il est un Wittelsbach) et surtout handicapé par le fait de ne jamais avoir été ordonné prêtre. Son relais sur place est le vicaire général Jean de Chokier (1571-1656), issu d'une vieille famille liégeoise ${ }^{52}$.

L'attitude de Des Marets est ambiguë. D’un côté, il cherche à respecter en apparence les intérêts des États-Généraux et de la France, qui veulent maintenir la neutralité liégeoise et une coexistence pacifique. Dans la correspondance diplomatique, les agents du roi de France rapportent en détail et en traduction française les résolutions du Conseil de la ville de Maastricht, en date du 3 février 1633, garantissant la liberté des deux cultes, les passages de l'un à l'autre et, surtout, interdisant les injures ou les entraves des deux côtés ${ }^{53}$. De ce fait, Des Marets insiste en plusieurs occasions sur sa prétendue douceur, par exemple dans sa Chandelle mise sous le boisseau à la fin de l'année 1634, où dès la préface aux Liégeois il dénonce "[leurs] Ecclesiastiques, principalement les Reguliers, [qui 1]'ont tiré en ceste lice, \& [qui 1]'ont harcelé par diverses escarmouches paravant que de pouvoir [s]'engager à ce combat ${ }^{54}$. Plus loin, il prend à témoin ses fidèles:

«Ceux qui me cognoissent en particulier ou qui frequentent nos assemblées publiques, me sçavent assez esloigné de violence. J'ay esté tiré contre mon humeur en ces contentions; $\&$ toute ma ferveur n'est que glace, en comparaison de la fureur de mes adversaires; mes

50. Alfred Poncelet, Histoire de la Compagnie de Fésus dans les anciens Pays-Bas : établissement de la Compagnie de fésus en Belgique et ses développements jusqu'à la fin du règne d'Albert et d'Isabelle, Bruxelles, Académie royale de Belgique, vol. 1, 1927, p. 246-257 et p. 307-310.

51. Voir par exemple plusieurs passages de S. DES MARETS, La Chandelle mise sous le boisseau par le clergé romain, ou Considération théologique sur le mandement épiscopal publié par tout le diocèse de Liège le 24 de may, réitéré le 5 de juillet ensuivant [...] auquel la lecture des livres des Réformés, et notamment celle des Sainctes Escritures en langue vulgaire, est absolument prohibée, Maastricht, Boucher, 1635 [1634].

52. Ulysse CAPITAINE, "Chokier (Jean de) ou de Chokier de Serlet", Biographie nationale publiée par l'Académie royale des sciences, des lettres et des beaux-arts de Belgique, Bruxelles, Thiry, vol. 4, 1873, col. 85-91.

53. MAE, CP Liège, vol. $1, \mathrm{f}^{\circ} 83-84$.

54. S. Des MARETS, La Chandelle..., op. cit., n.p. 
predications n'ont rien de violent, n'y traittant que bien rarement des controverses, \& ce avec toute sorte de douceur $\|^{55}$.

En cela, il agit bien comme n'importe quel pasteur français du royaume qu'il a quitté. Pourtant, le contexte local est déterminant, car d'un autre côté, Des Marets se plaint - discrètement, il est vrai - de la trop grande douceur des autorités néerlandaises vis-à-vis du catholicisme, alors qu'elles devraient selon lui favoriser son Église qui, dans les sept provinces, aurait été la seule à être publique. Il s'épanche sur cette question dans sa correspondance avec Rivet. Il faut dire que les périodes de véritable soutien du pouvoir politique à une éventuelle calvinisation sont rares: même si les Pays de la Généralité et Maastricht apparaissent comme des enjeux particuliers et lient conquête militaire et expansion du protestantisme ${ }^{56}$, la prudence est de mise, surtout qu'à Maastricht la capitulation garantit l'existence de deux Églises publiques. Dès le début de son ministère, Des Marets condamne la visite qu'ont accordée deux membres du Conseil d'État des Provinces-Unies, de passage en ville, aux dignitaires du clergé, alors qu'ils «ne se sont point du tout enquis de l'Estat de [leurs] Eglises, et en tout le temps qu'ils y ont sejourné, n'ont esté à [s]on advis que deux fois au presche» - pour conclure, de façon cinglante, que «la religion Romaine qui devoit y estre traittée comme une Esclave, est carressée de ceux qui deussent le plus la mespriser ${ }^{57}$. La protection des États-Généraux est toutefois nécessaire pour l'Église française, d'autant que les rapports de forces locaux restent tendus: par exemple, en mai 1633, le consistoire doit écrire à La Haye pour se plaindre du retard pris par le Magistrat de Maastricht pour transmettre un ordre tendant à faire célébrer un jeûne national dans les Églises réformées. Il en profite alors, sans doute à l'initiative de Des Marets qui tient la plume, pour regretter publiquement l'état de sa religion dans la ville, "cependant que l'idole s'y prommeine tous les jours avec tant de Pompe \& de liberté "58. Même lorsque l'Église française réclame des allégements d'impôts pour ses membres auprès des États-Généraux, il s'agit de condamner le clergé adverse et d'en faire un prétexte de controverse, puisqu'une solution est proposée pour trouver l'argent: "Vos très illustres seigneuries pourroient pour suppléer à ce deffaut décimer nostre Clergé qui n'est que trop gras " ${ }^{59}$. Le recours fréquent aux États-Généraux pour dénoncer les clercs catholiques se perçoit aussi dans la ville de Limbourg ${ }^{60}$, ou à un niveau plus régional ${ }^{61}$, et n'est donc pas une

55. Ibidem, p. 156.

56. W. FRIJHOFF, «La coexistence confessionnelle dans les Provinces-Unies. Un régime de connivence à plusieurs vitesses", in Martin DUMONT (éd.), Coexistences confessionnelles en Europe à l'époque moderne. Théories et pratiques, XVI $I^{-} X V I I^{e}$ s., Paris, Cerf, 2016, p. 105-124, notamment p. 108-109.

57. BU Leyde, BPL 297, f ${ }^{\circ} 11-12$, lettre écrite de Maastricht le 8 avril 1633.

58. NA, inv. 1.01.02, vol. 5818 (liasse Maastricht), f ${ }^{\circ}$ 456, lettre du 14 mai 1633.

59. Ibidem, $\mathrm{f}^{\circ} 428$, mémoire du $1^{\text {er }}$ juillet 1633 .

60. Voir par exemple NA, inv. 1.01.02, vol. 12 553.9, lettre du consistoire de l'Église française de Limbourg aux États-Généraux, 12 février 1633.

61. Voir par exemple NA, inv. 1.01.02, vol. 5821 (liasse Maastricht), f ${ }^{\circ}$ 376-377, été 1633 , mémoires adressés par les Églises de Maastricht et d'Outre-Meuse aux États-Généraux. 
spécificité de Maastricht, même si l'opposition avec Liège se cristallise dans cette dernière ville pour des raisons institutionnelles. Le contexte est donc très différent de celui du royaume de France, où il aurait été impensable de solliciter les autorités politiques à des fins de protection, mais aussi différent des Provinces-Unies où la question catholique se pose en d'autres termes.

Les attaques de part et d'autre sont nombreuses. En une vingtaine de mois jusqu'en 1634, ce ne sont pas moins d'une douzaine de mandements épiscopaux liégeois qui paraissent contre les réformés et qui sont envoyés à Maastricht, malgré les contestations néerlandaises. Les décisions se répètent, preuve de leur efficacité relative, mais aussi de la détermination des autorités liégeoises, largement composées de clercs, malgré quelques réserves dans le Magistrat de la ville elle-même ${ }^{62}$. Plus d'une cinquantaine de pamphlets sont échangés entre 1633 et 1635 , en français ou en latin ${ }^{63}$. Par leurs modalités, notamment leur fonctionnement par chaînes, ces controverses ressemblent à celles que l'on trouve à la même époque en France. Des Marets dote son Église de moyens techniques pour contrer les catholiques, notamment par la quête d'un imprimeur, dès le premier semestre 1633, car lui et son collègue de l'Église néerlandophone, l'Allemand Philippus Ludovicus (1592-1667), ont déjà des pièces à faire imprimer, notamment une conférence qu'ils ont tenue le 14 avril précédent face à des cordeliers de Louvain sur le sacrifice de la messe ${ }^{64}$. Les 19 avril et 3 mai 1633, une ordonnance du prince-évêque Ferdinand contre les protestants inclut précisément un article interdisant l'installation d'imprimeurs ${ }^{65}$. Finalement, Ézéchiel Boucher met des presses à disposition des réformés de Maastricht, ouvrant de nouvelles perspectives.

Par ses thèmes aussi, la controverse liégeoise et maastrichtoise ressemble fort à ce que l'on retrouve en France à la même époque: la messe, le mariage des pasteurs, l'autorité de l'Église, de la Bible, de la Tradition, etc., au point que l'historien Olivier Donneau la voit, à juste titre, "comme une annexe du champ polémique français ${ }^{66}$. Il existe pourtant des originalités dans le traitement concret de ces débats. Des Marets doit mobiliser des arguments qui mettent en jeu ses fidélités et ses engagements que nous qualifierions de "politiques". Un des éléments déclencheurs de la mécanique est la confusion orchestrée par le

62. David LENOIR, Histoire de la Réformation dans l'ancien pays de Liége, Bruxelles, Librairie chrétienne évangélique, 1861, p. 295.

63. B. Demoulin, J.-L. Kupper, Histoire de la principauté..., op. cit., p. 165; Olivier DONNEAU, «La controverse antiprotestante", in Paul BRUYĖRE, Alain MARCHANDISSE (éd.) Florilège du livre en principauté de Liège du IXe au XVIII siècle, Liège, Société des bibliophiles liégeois, 2009, p. 268-269 et p. 301.

64. BU Leyde, BPL 297, f ${ }^{\circ}$ 7-8, lettre à Rivet du 3 mai 1633. Les actes de cette conférence sont finalement publiés dans S. DES MARETS, Monachomachia, sive Vindica pro Veritate Religionis Reformatce, adversus Matthice Hauzeur Franciscani Leodiensis, ac nonnullorum aliorum Monachorum strophas, argutias E calumnias, Maastricht, Boucher, 1634, p. 280-351. Sur le collègue de Des Marets: Willem BAX, D. NAUTA, "Ludovicus, Philippus", in D. NAUTA et alii (éd.), Biografisch lexicon voor de geschiedenis van het Nederlandse protestantisme, Kampen, Kok, vol. 1, 1978, p. 145-146.

65. Voir un exemplaire imprimé en 1633 à Liège par Ouwerx à la BU Liège, R $177 \mathrm{E}, \mathrm{f}^{\circ} 12$. Publié dans D. LENOIR, Histoire..., op. cit., p. 266-271.

66. O. DONNEAU, «La controverse...», art. cit., p. 268. 
clergé liégeois entre évêché (la principauté) et diocèse (au sein duquel se trouve Maastricht), pour légitimer l'application en ville de mesures anti-protestantes. Une des réponses, précisément théorisée par Des Marets, consiste à reconnaître la légitimité du prince sur sa principauté, mais à combattre celle de l'évêque sur son diocèse, a fortiori la partie se trouvant en dehors de l'État à la tête duquel il se trouve ${ }^{67}$. Certains sujets de controverse provoqués par le contexte local (par exemple l'interdiction de la lecture de la Bible en langue vernaculaire par le prince-évêque en 1634 qui amène Des Marets à défendre la position réformée) permettent en réalité d'aborder les points contestés de façon beaucoup plus globale.

De ce point de vue, le pasteur se trouve dans une situation plus libre et plus active que celle de ses confrères exerçant sous le régime de l'édit de Nantes. Il répond d'ailleurs par une stratégie qui aurait été condamnée par les consistoires et synodes français (et qui lui vaut des ennuis disciplinaires à Maastricht aussi, on y reviendra): la contrefaçon et l'usage de faux discours. Cette pratique existe ponctuellement en France, mais ne devient jamais aussi systématique que durant ces années 1633-1635 à Liège et Maastricht. Les chaînes s'entremêlent et il est parfois difficile de s'y retrouver, mais il semblerait que les premières attaques de ce genre soient lancées par le récollet de Liège Matthias Hauzeur dans un opuscule moquant l'arrivée du prince d'Orange dans la région en pastichant un discours réformé ${ }^{68}$. Des Marets s'en offusque et prévient Rivet qu'il en écrit la réfutation, avant même que sa bibliothèque n'arrive de $\operatorname{Sedan}^{69}$. Il emploie rapidement les mêmes armes, par exemple en rédigeant L'esprit $d u$ bourguemaistre Beckman retourné de l'autre monde, dans lequel il fait parler un dirigeant municipal liégeois décédé quelques mois auparavant, tout en usant parallèlement de formes plus usuelles, comme une Remontrance très humble sur le mandement épiscopal de Liège du 19 avril $1633^{70}$. Dans le domaine de la contrefaçon, son ouvrage le plus achevé est l'Abrégé de la voie de salut, qui se présente comme un catéchisme catholique, avec des commentaires critiques annoncés comme ceux des jésuites de Maastricht, mais dont la teneur calviniste ne fait aucun doute ${ }^{71}$. Cet ouvrage lance une chaîne aboutissant à l'interdiction

67. J. LÉONARD, «Samuel Des Marets, un pasteur de Maastricht contre le prince-évêque de Liège: La Chandelle mise sous le boisseau par le clergé romain (1634)", in Anne WAGNER, Michel MARGUE (éd.), L'évêque contesté. Étude des résistances à l'autorité épiscopale et à son image des Pays-Bas méridionaux à l'Italie du Nord du $X^{e}$ au XVII siècle. Falons pour une enquête, Paris, Classiques Garnier, à paraître.

68. Des Marets évoque cet ouvrage sous le titre La Bien-venuë au Prince d'Orange, mais je n'ai pas réussi à le consulter. Cunibertus SLOOTS, «Pater Matthias Hauzeur O.F.M. Een Polemist - Bijzonder Tegen Samuel Maresius - Uit de 17de Eeuw", Nederlands Archief voor Kerkgeschiedenis, 33, 1941-1942, p. 162-184. 69. BU Leyde, BPL 297, f 5-6, 29 décembre 1632.

70. Ces pièces ont été publiées par U. CAPITAINE (éd.), "Pièces relatives au mandement publié à Liège le 19 avril 1633 contre les protestants", Bulletin de l'Institut archéologique Liégeois, 2, 1854, respectivement p. 276-283 et p. 269-275.

71. [S. Des MARETS], Abregé de la voie de Salut, ou declaration familiere de la verité Chrestienne, Par forme de Catechisme, pour confirmer les Catholiques \& instruire les douteux ou errants. Avec Les observations des RR. Pères fesuites de la ville de Maestrich sur iceluy, Liège [Maastricht?], Jean Tournay [Ézéchiel Boucher?], 1633. Selon D. NAUTA, Samuel Maresius, op. cit., p. 128, cet ouvrage a été en réalité imprimé à Sedan chez Jannon. 
épiscopale de la lecture des livres contrefaits par Des Marets, mais aussi de la Bible en français, ce qui suscite des faux mandements épiscopaux, une défense latine de Chokier ${ }^{72}$, puis la Chandelle mise sous le boisseau, dont il a été question, enfin sa réfutation par Chokier et surtout par le jésuite de Maastricht Godfried Wandelman (1591-1654) ${ }^{73}$, pour se limiter aux principales productions. Des Marets constitue systématiquement une cible de choix, puisque même lorsqu'une conférence implique un autre pasteur francophone, comme Godefroy Hotton (1596-1656), installé à Limbourg, son collègue de Maastricht est attaqué dans les actes $^{74}$.

L'emploi de la contrefaçon est observé par les autorités politiques ${ }^{75}$. Il suscite les réactions indignées des catholiques et une défense parfois gênée de Des Marets, qui plaide toutefois que l'on reconnaît clairement l'identité calviniste de l'auteur dans ses pastiches. Certains passages de ces ouvrages permettent de penser que le pasteur croit lutter contre un catholicisme assez particulier. Dans l'Abrégé de la voie de salut, il développe longuement des éléments qui dénoncent une spiritualité tridentine fortement marquée selon lui par la piété espagnole, comme les saints, la Vierge, les reliques, les images, ou surtout le chapelet ${ }^{76}$, alors même qu'on peut s'interroger sur le caractère réellement espagnol de cette spiritualité plus globalement tridentine et comparable à celle que les Wittelsbach promeuvent ailleurs ${ }^{77}$. Dans le même état d'esprit, son épître dédicatoire de la Chandelle mise sous le boisseau regrette l'état affligé des peuples soumis aux clercs:

«On entretient le vulgaire d'Images, de Musiques, de Macerations, de Processions \& de Pompes, cependant qu'on luy soustrait le pain spirituel de la Parole de Dieu; On luy propose des Legendes, des Chappelets, des Indulgences, des Agnus Dei \& choses semblables, cependant qu'on luy oste le moyen de s'instruire pour la vie, \& de se consoler en la mort, ès divines Escritures $»^{78}$.

72. Jean DE CHOKIER, Parcenesis ad Hareticos, et alios Ecclesice hostes et mastiges, Cologne, Kinkius, 1634.

73. J. DE CHOKIER, Apologeticus adversus Samuelis Maresii Oppidi Trajectensis ministri librum, cui Titulum fecit Candela sub modio posita per Clerum Romanum, Liège, Léonard Streel, 1634; Théodose Tranquille [Godfried Wandelman], La Chandelle esteinte et puante, de Samuel Des Marets, Ministre de la Pretendue Église Reformée, à Maestricht: response à l'escrit intitule La chandelle mise sous le boisseau par le clergé romain, Liège, Ouwerx, 1635. Pour l'attribution et la contextualisation de la controverse: Joep VAN GENNIP, Controversen in Context. Een comparatief onderzoek naar de Nederlandstalige controversepublicaties van de jezuïeten in de zeventiende-eeuwse Republiek, Hilversum, Verloren, 2014, p. 232-258.

74. Compendium conferentice Lymburgensis. Inter F. Matthiam Hauzeur ordinis FF. MM. Recollectorum, Conventis Leodiensis; \& D. Hottonium Archi-Ministrum Lymburgensem. Et Reprobatio peremptoria totius patrocinii ac supplementi Archi-Ministri Trajectensis, pro suo Hottonio, Liège, Sauveur, 1633.

75. NA, inv. 1.01.02, vol. 5820 (liasse Maastricht), f³96-397, lettre du 10 juin 1634 aux ÉtatsGénéraux.

76. [S. Des MARETS], Abregé..., op. cit., p. 84-107. Sur la piété qui s'étend dans certaines zones de la "Dorsale catholique», voir par exemple P. MARTIN, "La Lorraine des années 1580-1630, terre de spiritualité espagnole?", Revue d'histoire de l'Église de France, 90/1-224, 2004, p. 147-159, en attendant les actes du colloque Une piété lotharingienne: foi publique, foi intériorisée (XII - XVIII siècle) tenu à Lyon du 8 au 10 novembre 2017.

77. Damien TRICOIRE, La Vierge et le Roi: politique princière et imaginaire catholique dans l'Europe $d u$ XVII siècle, Paris, Presses de l'université Paris-Sorbonne, 2017.

78. S. Des MARETS, La Chandelle..., op. cit., n.p., épître dédicatoire. 
Pour Des Marets, pas de doute: tout cela est dû à l'influence espagnole. Faisant semblant d'écrire comme un jésuite de Maastricht, il se demande "pourquoy alleguer les grands Chappelets des Espagnols, que l'on sçait estre les plus grands hypocrites du monde ? ${ }^{79}$ et souligne les effets positifs de la fin de la domination espagnole: "Depuis que nous sommes aux Hollandois nous n'avons tellement oublié nostre Espagnol, qu'il ne nous souvienne encores de la quatrieme Reigle qui se trouve au commencement de l'Indice Expurgatoire dressé par le sacré Conseil de l'Inquisition ${ }^{80}$.

Il est probable que s'attaquer à l'identité espagnole soit une stratégie pour ménager certaines susceptibilités liégeoises. Il ne faut cependant pas minimiser la véritable hargne des pasteurs réformés contre l'Espagne: c'est presque naturel dans les Provinces-Unies, mais c'est aussi un sentiment largement partagé chez ceux qui exercent en France, et qui mêlent fréquemment dans leurs dénonciations l'Espagne, les avatars de la Ligue, les jésuites et les régicides ${ }^{81}$. Dès le début de son ministère à Maastricht, Des Marets ne fait pas mystère, auprès de son correspondant Rivet, de ses doutes sur la position politique des clercs catholiques du pays de Liège, et même de sa cité proprement dite: il craint ainsi un siège "veu le grand nombre d'Ecclesiastiques qu'il y a en ceste ville et d'Espagnolisés ${ }^{82}$. Il se révèle toutefois plus prudent dans la controverse imprimée, et attaque le caractère espagnol de ses adversaires pour se maintenir sur un segment acceptable par ses protecteurs néerlandais. Dans sa remontrance contre le mandement liégeois d'avril 1633, il essaie ainsi de convaincre que l'on peut être en même temps un bon sujet liégeois et un calviniste, contre les clercs qui disent le contraire et qui sont, précisément, "des Pensionnaires Espagnolisés» et des "Mouchards de l'Inquisition" ${ }^{83}$. Cette déconnexion entre identité politique et identité confessionnelle est à la même période acceptée par ses confrères français, dans le contexte du ministériat de Richelieu et contre le parti dévot vu comme lié à l'Espagne. Dans son discours imaginaire mettant en scène le défunt bourgmestre Guillaume de Beeckman, la position de Des Marets l'amène à revendiquer la liberté d'expression et de conscience pour tous, ce qui est une stratégie proche de celle de ses coreligionnaires français, mais que l'on ne retrouve pas ailleurs aux Provinces-Unies, et que sa correspondance avec Rivet montre être une ruse.

79. [S. Des MARETS], Abregé..., op. cit., p. 105-106.

80. Ibidem, p. 113.

81. J. SoLÉ, "L'image des jésuites chez les réformés français du XVII" siècle», in Geneviève DEMERSON et alii (éd.), Les jësuites parmi les hommes aux XVI et XVII siècles, Clermont-Ferrand, Association des Publications de la faculté des Lettres et Sciences humaines, 1987, p. 231-234; Gerrit VANDEN Bosch, "L'image des jésuites dans la République des Provinces-Unies au Siècle d'or: cinquième colonne ou mythe entretenu ?", in Pierre-Antoine FABRE, Catherine MAIRE (éd.), Les antijésuites. Discours, figures et lieux de l'antijésuitisme à l'époque moderne, Rennes, Presses universitaires de Rennes, 2010, p. 429-453.

82. BU Leyde, BPL 297, f 15-16, lettre du 3 août 1633.

83. U. CAPITAINE (éd.), "Pièces relatives...", art. cit., p. 272-273. 
Il écrit ainsi:

«En la naissance du schisme, et quand l'heresie estoit encores en semence et en herbe, je n'aurois point improuvé ces placards: Ils eussent esté tolerables au temps que nous estions obligés de nous habiller à l'Espagnole, et de donner cours à l'Inquisition: Je m'en serois teu si l'erreur estoit encores confiné dans le fond de la Hollande, et par la multitude de ses Canaux empesché de venir jusques à nous. [Mais] les Canons qui leur ont ouvert les portes de Maestrecht, et qui ont introduit leur Religion en nostre voisinage, ont rompu les chaisnes de nostre servitude, et nous ont redonné nostre ancienne Liberté» ${ }^{84}$.

Chasser les réformés serait:

«redonner en nostre Ville le haut du pavé aux Espagnols et aux Espagnolisés: Vous Messieurs les Ecclesiastiques qui avés une si grande Liberté dans Maestrecht et és autres lieux de leur obeissance, qui jouissez soub leur authorité et protection de plus de deux cens cinquante mil florins de revenu ne deviés vous pas user pour ce respect de quelque moderation à l'endroit des Reformés, de peur que chassés de leur patrie et arrachés des mammelles de leur mère, ils n'aillent poursuivre des devolus dessus vos benefices?” 85

Ces arguments sont encore avancés à la fin de l'année 1634 dans La Chandelle mise sous le boisseau, notamment dans une préface adressée aux Liégeois, mettant en cause l'engagement espagnol des clercs, surtout de Chokier qui avait avoué «devoir marier sa plume avec l'espée d'Espagne» et exhorté le roi de France à se départir de son alliance avec "des Heretiques Rebelles». Des Marets fait bien la différence entre identité confessionnelle et engagement politique, puisque selon lui:

"C'est son genie [celui de Chokier] plus Espagnol que Catholique Romain, qui lui fait tenir ou approuver ce langage: car ceux d'entre vous qui peseront les choses au trebuchet de la raison, recognoistront bien que le voisinage des Hollandois vous a esté autrement doux, \& je l'ose dire, autrement profitable que celui des ennemis: Jamais nos soldats n'ont foullé vos surceans, violé leurs femmes, bruslé leurs vilages \& pillé leurs Eglises, comme si souvent l'ont fait ceux de l'autre parti» 86 .

Le jésuite Wandelman réfute implicitement cette interprétation et lie au contraire identités politique et confessionnelle. Dès son épître dédicatoire à Chokier, il accuse Des Marets d'avoir «vilainement outragé tout l'Estat de Liege, $\&$ le Clergé plus que le reste ${ }^{87}$. Pourtant, la position du pasteur de Maastricht est susceptible de faire mouche, surtout que dans les années 1634 et 1635 les liens entre la France et les Provinces-Unies se resserrent, notamment par la signature de traités qui prévoient des partages territoriaux en cas de conquête contre les Espagnols, et cela suscite beaucoup d'intérêt pour la neutralité liégeoise. Cette montée des tensions touche directement Maastricht, assiégée par les troupes du marquis d'Aytona en juin $1634^{88}$. La correspondance diplomatique française avec la principauté de Liège montre que l'on sait faire la différence entre catholiques

84. Ibidem, p. 277.

85. Ibidem, p. 278.

86. S. Des MARETS, La Chandelle..., op. cit., n.p., préface.

87. T. TRanQuille [G. WANDElman], La Chandelle esteinte..., op. cit., p. 4.

88. A. Waddington, La République..., op. cit., vol. 1, p. 232. 
et parti pro-espagnol. Dans une instruction à l'abbé de Mouzon en mai 1634, il est ainsi question à la fois de rassurer les Liégeois quant à la volonté du roi de conserver le catholicisme, mais aussi de "les retirer de la dépendance d'Espagne qui ne peut qu'ouvrir la porte à leur tort et à leur ruine ${ }^{89}$. Dans le même temps, les Français se préoccupent beaucoup d'empêcher des négociations entre Espagnols et Néerlandais qui les prendraient de vitesse, et qui pourraient inclure Maastricht ${ }^{90}$.

Ces controverses et ces circulations de faux ont considérablement détérioré les conditions de la coexistence confessionnelle au quotidien. Au cours de l'année 1634, Des Marets se plaint à plusieurs reprises de l'attitude négative des jésuites à son égard:

«Et quant à ce que je ne les saluë point, je ne croy pas estre obligé de commencer le compliment avec eux; et jamais ils ne m'ont salué ni regardé que de travers depuis que je suis en ceste ville, et dès un an devant mes observations publiées soubs leur nom [l'Abrégé de la voie de salut], dequoy je me justifieray ailleurs" ${ }^{91}$.

Quelques mois auparavant, il rapporte déjà à Rivet que les tensions amènent ses adversaires à revendiquer son départ: «On m'asseure que Ceux de Liege veulent faire une grande instance vers Nosseigneurs les Estats pour m'esloigner d'icy " ${ }^{92}$. Des Marets doit par ailleurs faire face à la surveillance des autorités et à certaines inimitiés jusque dans son propre camp. C'est qu'il tente d'enraciner à Maastricht une Église française sous protection du duc de Bouillon, du prince d'Orange et des États-Généraux, au risque de tensions avec les autorités synodales wallonnes et avec l'Église néerlandophone.

\section{Établir Une Église françaISE? Le RAPPORt de Des Marets À La discipline}

Parallèlement à ces controverses, et contribuant à forger une identité particulière, le travail principal de Des Marets, au quotidien, consiste à établir et à consolider son Église. Cette dernière doit être, dans son esprit, une Église «française» sans être une Église "de France», et cela pose quelques problèmes disciplinaires et politiques qui sont intimement liés. Le nom que donnent Des Marets et ses collègues à leur communauté dans les sources ecclésiastiques est assez révélateur. L'intégration ultérieure de l'Église aux structures du synode des Églises wallonnes des Provinces-Unies, et les termes en usage dans l'historiographie, ont tendu à présenter cette congrégation comme une "Église wallonne»" ${ }^{93}$. Pourtant, les pasteurs usent systématiquement de l'expression «Église française»,

89. MAE, CP Liège, vol. 1, fo 109 bis-111.

90. Voir par exemple MAE, CP Hollande, vol. 14, f 100, copie d'une lettre à Hercule de Charnacé, 18 mars 1633.

91. BU Leyde, BPL 297, f ${ }^{\circ} 22-23$, lettre du 14 octobre 1634. Ces mots sont presque textuellement repris par S. DES MARETS, La Chandelle..., op. cit., p. 157.

92. BU Leyde, BPL 297, f० 21, lettre du 21 juin 1634.

93. F.-H. GAGNEBIN, "Liste...", art. cit.; Jhr. W. C. QUARLES VAN UFFORD, "Geschiedenis der Waalsche Gemeente te Maastricht", in Gedenkboek der Nederlandsche Hervormde Gemeente van Maastricht, 1632-1932, Maastricht, Boosten \& Stols, 1932, p. 347-360. 
que ce soit lorsqu'ils signent un ouvrage, ou dans le registre des baptêmes et mariages de ces années 1632-1636, et même au-delà si l'on regarde le registre du consistoire qui est conservé à partir de 1646, alors même que ces documents sont aujourd'hui archivés avec les dossiers de la Waalse gemeente Maastricht ${ }^{94}$.

Cette Église française semble bien fragile au départ. Les registres le montrent, il n’y a que 11 baptêmes célébrés en 1632-1633, mais déjà 20 en 1634 et 32 en 1635. Les mariages, eux, sont stables (respectivement 14 et 13 en 1634 et 1635). Il s'agit essentiellement de marchands et de soldats, et il est possible que parmi les fidèles se soient glissés des individus venus de Liège ou de Sedan ${ }^{95}$. L'impression de fragilité se confirme à la lecture de la correspondance entre Des Marets et Rivet, alors à La Haye et au cœur du pouvoir orangiste, et qui a peut-être connu dix ans plus tôt les mêmes questions sur son identité «française». Le pasteur de Maastricht rapporte à de nombreuses reprises ses espoirs et ses doutes sur la croissance de l'Église réformée française, au gré des événements, qu'ils soient militaires (l'avancée des Espagnols) ou sanitaires (des épidémies de peste), faisant affluer ou repartir les fidèles. Son souci pastoral est visible. Même si son regard se porte essentiellement sur sa ville, ses lettres évoquent fréquemment "nos Églises», incluant les communautés du Limbourg et de l'Outre-Meuse sous contrôle des États-Généraux. La fin de l'année 1632 et le début de 1633 constituent une période d'exaltation, il peut même écrire que l' "Eglise s'accroist icy merveilleusement ${ }^{96}$. Il est beaucoup moins enthousiaste au cours des mois suivants.

Les rares sources nous montrent une Église structurée, particulière mais ressemblant dans ses institutions à ses sœurs de France ou des Provinces-Unies. Nous n'avons malheureusement son règlement intérieur que pour $1646^{97}$, mais il est probable qu'il reprenne des éléments plus anciens. On y distingue un consistoire, des anciens, des diacres, un maître d'école. Dans les registres de baptêmes et de mariages, on voit aussi au hasard des noms un sonneur, un chantre, un lecteur, l'imprimeur Boucher pour cette dernière fonction importante. Sur quatre sujets cependant - sans compter la controverse confessionnelle proprement dite, mais en lien avec elle - Des Marets doit se montrer combatif: l'obtention d'un collège, le choix de collègues pour Maastricht et les alentours, l'amélioration du lieu de culte et le paiement des gages par les États-Généraux. Sa stratégie sur ces sujets est avant tout l'adresse aux États-Généraux, soit directement ${ }^{98}$, soit par l'intermédiaire de protecteurs puissants (Rivet donc,

94. Regionaal historisch Centrum Limburg, Maastricht (désormais RHCL), inv. 11.01.78.156, Registre de tous les Enfans qui ont esté baptisés en l'Eglise françoise recueillye dans ceste ville de Maestricht depuis le Mois de Novembre de l'an 1632 (1632-1643); inv. 21.279.2, registres du consistoire (1646-1733) comprenant les Reiglemens de l'Eglise Françoise de Mastrecht, arrestés au Consistoire (p. 1-2).

95. RHCL, inv. 11.01.78.156. Voir P. DENIS, "Les réfugiés du pays de Liège au XVI siècle", in ID. (éd.), Protestantisme aux frontières..., op. cit., p. 91-98, p. 93-94.

96. BU Leyde, BPL 297, f ${ }^{\circ}$ 5-6, lettre du 29 décembre 1632.

97. RHCL, inv. 21.279.2, p. 1-2, Reiglemens de l'Eglise Françoise de Mastrecht, arrestés au Consistoire. 98. NA, inv. 1.01.02, vol. 5 818-5 821 (liasse Maastricht, 1632-1636). 
mais aussi éventuellement le duc de Bouillon). Dès février 1633 est envoyé un Mémoire de l'Église Reformée de Maestricht pour estre presenté à Nosseigneurs les Estats en dix-sept points, synthétisant les sujets d'inquiétude dans un contexte où les catholiques sont démonstratifs au sein de l'espace public, mais aussi suspectés de renseigner les Espagnols et les autorités liégeoises sur la fréquentation du culte ${ }^{99}$. C'est encore aux États-Généraux que l'Église s'adresse lorsqu'il s'agit de placer les pasteurs ou d'en recruter en décembre 1634, en partie pour essayer de se débarrasser de Jacques de La Grève $\mathrm{e}^{100}$.

Les cas sont nombreux, les lettres et mémoires circulent d'autant plus intensément que face à Des Marets s'accumulent les obstacles. En effet, à peine un an après son installation, il consacre plusieurs lettres à dénoncer «Les Flamends envieux de l'accroissement de nostre Eglise", à cause de rivalités autour des lieux de culte ${ }^{101}$, d'autant plus qu'il aime rappeler que l'Église française a été établie avant la néerlandaise ${ }^{102}$. De ce fait, Ludovicus, son collègue de l'Église néerlandophone, est désigné comme un "ennemi formé» ${ }^{103}$, peut-être parce que cet ancien prédicateur du prince-électeur palatin Frédéric V, pendant son bref règne à la cour de Bohème, est un personnage d'envergure qui lui fait de l'ombre. Les relations ne sont pas meilleures avec La Grève, le second pasteur français de Maastricht, depuis le début de l'année 1634. Des Marets écrit ainsi à Rivet: «J'ay tousjours mon espine à mes costés en Mr. de la Greve dont nostre Eglise est fort mal ediffiée ${ }^{104}$. La situation est d'ailleurs aggravée en octobre 1634 par la perte du petit culte champêtre secondaire de Dalhem, qui fait se replier La Grève définitivement sur la seule ville. Il se peut que Des Marets, si actif et impliqué, ne supporte pas la collégialité (pourtant fréquente ailleurs) de la charge pastorale. Quoi qu'il en soit, la situation est grave à ses yeux en janvier 1635, et il la résume ainsi à Rivet, montrant son isolement:

«j'ay une cour qui parle Asdodien et qui pointille sur tout, un collegue incapable et malaffectionné et qui est en achoppement au publicq, des confreres flamends, ennemis de ma nation, jaloux de ma personne et qui ont plus de soing de diminuer nostre trouppeau que de destruire le mensonge, un synode esloigné où je ne me peux jamais trouver, et qui ne peut ne cognoissant rien de nostre Estat nous apporter grand secours, des compagnons sur le plat pays qui se considerants francs du costé des ennemis se sont resolus de donner la classe à chacune de leurs Eglises à son tour, et par consequent de nous en forclorre ${ }^{105}$.

99. Ibidem, vol. 5 818, f० 455-456, publié par D. NAUTA, Samuel Maresius, op. cit., p. 579-582 (avec la référence à une ancienne cote).

100. NA, inv. 1.01.02, vol. 5 820, f382, publié par D. NAUTA, Samuel Maresius, op. cit., p. 585 587 (avec la référence à une ancienne cote).

101. Voir par exemple un mémoire sans date sur la question, envoyé aux États-Généraux (NA, inv. 1.01.02, vol. 5 818, f $^{\circ} 427$ ), publié par J. W. C. QUARLES VAN UFFORD, "Geschiedenis...», art. cit., p. 349-350 (cet auteur le date du $1^{\text {er }}$ décembre 1633).

102. BU Leyde, BPL 297, f 17, lettre de Des Marets à Rivet, le 19 novembre 1633.

103. Ibidem, f $^{\circ} 19-20$, du même au même, 14 juin 1634 .

104. Ibidem, $\mathrm{f}^{\circ} 18$, lettre du $1^{\mathrm{er}}$ mars 1634 .

105. Ibidem, $\mathrm{f}^{\circ}$ 28-30, lettre du 31 janvier 1635. La "cour qui parle Asdodien» renvoie à Néhémie, 13, 24. 
La correspondance avec Rivet nous montre pourtant sa participation active à la campagne de libération du pasteur Cyrus Du Moulin de Limbourg, prisonnier des Espagnols à Namur en $1635^{106}$.

Cet isolement de l'Église française (et de Des Marets en particulier) visà-vis des institutions ecclésiastiques wallonnes, présenté comme dramatique à Rivet, est aussi la conséquence des stratégies du pasteur qui peut prendre quelques libertés en matière disciplinaire, peut-être comme il l'avait fait à Sedan. Dès le départ, il dépend des États-Généraux pour son établissement, tant institutionnel que matériel ${ }^{107}$. Les trois premiers pasteurs de Maastricht et de Limbourg, dont Des Marets, reçoivent même une commission le 2 février 1633 pour établir à leur tour des Églises et des ministres dans la région au nom des autorités politiques ${ }^{108}$. Au printemps 1633, Des Marets semble ainsi fier d'annoncer à Rivet: "Nous avons estably des Pasteurs presques partout [en Limbourg et Outre-Meuse] en vertu de l'authorité que Nosseigneurs les Estats generaux nous en ont donnés" et se réjouit d'avoir bientôt suffisamment de "Ministres François» (sept) pour organiser une "classe»109. Ce dernier terme renvoie à une réalité néerlandaise et wallonne, mais que Des Marets connaît bien, puisqu'il s'agit de l'équivalent d'un colloque en France. En Normandie et sans doute ailleurs - les deux mots sont synonymes, comme on le voit dans une liste des Églises réformées de France en 1660 où les provinces synodales sont toutes subdivisées en colloques, sauf celle de Normandie où l'on retrouve donc des classes ${ }^{110}$. Cet usage du vocabulaire des Églises françaises établies sous domination des États-Généraux ne signifie toutefois pas encore une réunion au synode wallon, même si Des Marets a conscience quelques semaines plus tard que ledit synode va s'intéresser à elles ${ }^{111}$. Les actes des réunions de cette institution, qui rassemble les Églises wallonnes des Provinces-Unies, regroupées à l'échelon inférieur en classes, montrent une certaine gêne autour des procédures suivies. Car si le synode wallon ne peut contester l'autorité des États-Généraux qui financent les gages des pasteurs, il ne peut davantage accepter d'avoir été totalement oublié quand il s'est agi de confirmer les nominations, même a posteriori. Si l'on en croit le règlement ultérieur de l'Église française de Maastricht: «En la vocation des Ministres, on suivra l'ordre des Eglises du paysbas en sorte que l'election s'en fera par le consistoire avec confirmation du Synode ou de la

106. Ibidem, $\mathrm{f}^{\circ} 28-30$, lettre du 8 septembre 1635 donnant des détails sur cette affaire.

107. Ibidem, f ${ }^{\circ} 3-6$, lettres des 29 novembre et 29 décembre 1632.

108. NA, inv. 1.01.02, vol. 5818 (liasse Maastricht), $\mathrm{f}^{\circ} 465-466$, lettres de l’Église réformée de Maastricht aux États-Généraux, 8 avril 1633, et vol. 5 821, f 375 (mémoire sans date, été 1633).

109. BU Leyde, BPL 297, f 9-10, lettre du 21 mars 1633.

110. Bibliothèque de Genève, fonds Court, 17, f $308-330$, Roole des Eglises Reformées de France avec les noms des pasteurs exerçants le saint ministere en la presente année 1660, en particulier $\mathrm{f}^{\circ}$ 309-311 pour la Normandie. Ce document a été publié: Théodore ClaPARÈDE (éd.), «Liste des Églises et des pasteurs réformés de France en 1660", Bulletin de la Société de l'histoire du protestantisme français, 15, 1866 , p. 511-526 et p. 577-582, sur ce point p. 514-515.

111. BU Leyde, BPL 297, f ${ }^{\circ}$ 7-8, lettre du 3 mai 1633. 
Classe ${ }^{112}$, ce qui semble être la procédure ordinaire pour un renouvellement. Pour un premier établissement, l'ingérence des autorités politiques n'est donc pas contestée, mais elle nécessite la collaboration du synode. Or celui-ci s'est déjà plaint en avril 1631 de ce que le Nîmois Mardochée Suffren a été établi sans son avis à Bois-le-Duc, et a accepté la situation tout en espérant ne plus être ainsi mis devant le fait accompli ${ }^{113}$. C'est pourtant exactement ce qui se passe à nouveau en 1632-1633 à Maastricht, en Limbourg et Outre-Meuse. Dès le synode wallon qui se réunit à Flessingue, en Zélande, en septembre 1632, il est question de députer des pasteurs aux États-Généraux pour:

«pourvoir aux moyens d'establir Eglises de nostre langue à Maestricht, Limbourg, Herstal et autre part s'il eschet, la Compagnie embrassant ceste affaire à cœur, comme de son devoir et de son zele, est d'avis qu'elle s'employera à cest establissement, et pour cest effet elle a nommé $M^{\text {rs }}$. de la Riviere et Massis et $M^{\mathrm{r}}$. de Beaufort, Ancien de La Haye, vers $M^{\text {rs }}$. les Estats-genereaux "114.

Cependant, ils sont pris de court, puisque les États-Généraux et la famille d'Orange ont donc déjà manœuvré, avec les conseils de Rivet, pour pourvoir les nouvelles communautés ainsi instituées et, pire, les pasteurs installés en octobre 1632 sont chargés par les États-Généraux, on l'a vu, de la nomination de nouveaux collègues des alentours, ce dont le synode se plaint ${ }^{115}$. Il faut toutefois préciser que l'acte de provision du pasteur Hotton à Limbourg, en octobre 1632, montre un grand flottement disciplinaire et use de formules prudentes permettant une régularisation ultérieure ${ }^{116}$. Il est probable que la nomination de Des Marets ait pris des formes comparables. En avril 1633, à Kampen, en Overijssel, la procédure du synode est suspendue, dans l'attente d'échanges avec les États-Généraux ${ }^{117}$. De son côté, Des Marets, en août 1633, juste avant le synode suivant de Bois-le-Duc, dans les Pays de la Généralité, semble encore espérer une situation de protection directe des autorités politiques, sans nécessairement s'unir aux institutions existantes, comme il l'écrit à Rivet:

«Car l'apostille donnée à leur requeste par Nosseigneurs les Estats, ne parle point de sujettion à leur Synode mais de conformité en discipline, et vous scavés que cellecy peut subsister sans l'autre comme il se prattique en France entre les Synodes Provinciaux, nous ne refuserons pourtant point la premiere pourveu qu'il s'y trouve jour sans y rien risquer ou de l'honneur de nostre Ministere ou de la liberté et droit de nos Eglises »118.

112. RHCL, inv. 21.279.2, registres du consistoire (1646-1733), Reiglemens de l'Eglise Françoise de Mastrecht, arrestés au Consistoire (p. 1-2).

113. [Émile BOURLIER (éd.)], Livre synodal contenant les articles résolus dans les synodes des Églises wallonnes des Pays-Bas, La Haye, Martinus Nijhoff, vol. 1, 1896, p. 364-365, art. 23 du synode des Églises wallonnes tenu à Dordrecht (2-4 avril 1631).

114. Ibidem, p. 373, art. 10. Le cahier de ces députés du synode est publié dans G.H.M. PosTHUMUs Meyjes, H. Bots, Johanna RoELEvink (éd.), Livre des actes des Églises wallonnes aux Pays-Bas (1601-1697), La Haye, Instituut voor Nederlandse Geschiedenis, 2005, p. 310-312.

115. G.H.M. Posthumus Meyjes, H. Bots, J. Roelevink (éd.), Livre des actes..., op. cit., p. 313 (requête du synode de Kampen aux États-Généraux, 1633).

116. NA, inv. 1.01.02, vol. 12 548.195.2.

117. [É. BOURLIER (éd.)], Livre synodal..., op. cit., vol. 1, p. 376-377, art. 23.

118. BU Leyde, BPL 297, f 15-16, lettre écrite à Rivet, alors à Bois-le-Duc, le 3 août 1633. 
C'est le modèle français qui est mis en avant, sans toutefois rejeter l'autorité des États-Généraux. L'adhésion au synode wallon n'est envisagée qu'à la condition de correspondre aux intérêts locaux. C'est sans doute une des lignes directrices de l'action de Samuel Des Marets, qui rappelle fréquemment ses droits et qui les couche sur le papier dans un mémoire rédigé vers juillet 1633, qu'il débute de façon révélatrice par ces termes: «Messeigneurs les Estats m’ont establi en la ville de Maestricht aux conditions suivantes ${ }^{119}$. À Bois-le-Duc, il est finalement décidé que les pasteurs nommés à la fin de l'année 1632 seraient confirmés, dont Des Marets qui siège à la réunion. Les nouvelles Églises sont présentées comme "desjà erigées par l'authorité de $M^{\text {rs }}$. les Estats-generaux", mais en précisant, de façon assez artificielle "ensuite de la requeste presentée par le Synode de ces Eglises Assamblées à Flessingues, en septembre 1632». Il est accordé que ces Églises formeront une classe ("de Limbourg» ou "d'OutreMeuse» selon les occurrences, parfois "de Maastricht») et se soumettront désormais à l'autorité des synodes, y compris en matière de recrutement ${ }^{120}$. Les tensions sont toutefois perceptibles quand on lit que la première condition demandée par ces Églises pour leur incorporation est:

«Que l'union soit faite et receue comme d'une classe ou d'un corps d'eglises jà establies, sans que le synode veuille cognoistre ou juger de leur establissement et de la vocation des pasteurs qui y servent, laquelle ne pourroit estre rendue douteuse ou litigieuse sans prejudicier à l'honneur de leur ministere et à la commission, données par Nos Seigneurs les Estats de leur propre mouvement pour ledit establissement ${ }^{121}$.

La prégnance du modèle français est évidente, puisque cette classe demande aussi à avoir «les mesmes droicts et [jouir] de pareille authorité, veu surtout l'esloignement et la qualité des lieux, que les colloques des eglises françoises qui respondent aux synodes provinciaux et en tout particulier ${ }^{122}$. Cette dernière condition n'est pas reprise et les nouvelles communautés doivent rentrer dans le rang. Aux réunions suivantes, la nouvelle classe ainsi constituée a, comme prévu, bien du mal à envoyer des députés, tant à cause de l'insécurité des routes que de problèmes financiers, et elle doit régulièrement présenter ses excuses. Cela renforce son autonomie effective, mais elle reprend des pratiques disciplinaires étrangères à la France, comme l'existence d'une représentation permanente à travers une Église entre deux réunions de la classe. Les actes de ces dernières, rares à cause des conditions, montrent la grande virulence des députés contre le catholicisme environnant et cette volonté d'autonomie. Fin février 1634, il est ainsi question de la lutte contre les "prestres de l'Antichrist" et de l'installation de nouveaux ministres, mais aussi des usages de la discipline des Églises des Pays-Bas, et des confessions de foi à la fois "gallica» (celle «de

119. NA, inv. 1.01.02, vol. 5821 (liasse Maastricht), f $\mathrm{f}^{\circ} 373$.

120. [É. BOURLIER (éd.)], Livre synodal..., op. cit., vol. 1, p. 379-380, art. 10.

121. G.H.M. Posthumus Meyjes, H. Bots, J. Roelevink (éd.), Livre des actes..., op. cit., p. 318, mémoire des Églises du Limbourg.

122. Ibidem. 
La Rochelle») et "belgica» ${ }^{123}$. Le synode regrette que la classe s'autorise ainsi à confirmer les pasteurs, ce qui relève de son autorité, et n'intègre pas toutes les demandes, comme celle d'user du catéchisme de Heidelberg au lieu de celui de Genève ou d'ajouter un article définissant le pape comme l'Antéchrist ${ }^{124}$. Les actes des classes suivantes montrent qu'on ne tient pas compte de ces rejets...

Des Marets, pourtant, n'est pas seul à l'initiative de cette liberté locale, et il peut même en pâtir : c'est visiblement lassée par les controverses publiées que la classe de Limbourg décide d'instituer des pasteurs chargés de la censure, à cause des "dangereuses consequences des livres imprimés sans le sceu des pasteurs de la classe ${ }^{125}$, et cela s'applique à la Chandelle mise sous le boisseau que Des Marets doit laisser passer entre les mains de son collègue La Grève, qu'il apprécie si peu, au risque des moqueries de Wandelman ${ }^{126}$. L'année 1635 est marquée par une forme de déliquescence de la classe, dont certaines Églises se dispersent au fur et à mesure des campagnes espagnoles.

C'est que la guerre pèse lourdement sur les conditions disciplinaires de la vie ecclésiastique. Dans le contexte des négociations d'un nouveau traité entre France et Provinces-Unies après celui de La Haye d'avril 1634 (finalement signé à Paris le 8 février 1635) et prévoyant des partages territoriaux ${ }^{127}$, de nombreuses rumeurs courent. Même si les tractations ne concernent finalement pas Maastricht, c'est ce que croit Des Marets qui écrit à Rivet le 13 décembre 1634 qu'«un bruict court icy si constant de la vent[e] de Maestricht et Limbourg au Roy [de France] par Messieurs les Estats Generaux»"128. Ces rumeurs proviennent peut-être de discussions autour de l'entrée de troupes françaises en ville entre septembre et novembre $1634^{129}$. La situation inquiète tant Des Marets qu'il rédige alors un mémoire très détaillé, en vingt-sept points, rassemblant les conditions qu'il veut mettre à une telle intégration au royaume ${ }^{130}$. Bien que l'on ignore quelle suite a été donnée à cette initiative, son contenu est édifiant. L'idée d'une union avec les Églises réformées de France n'est pas explicitement rejetée, mais il est demandé de conserver certains privilèges, ce que la structure de l'Ancien Régime permet par ailleurs, comme le montrent certains cas d'Églises isolées ou au statut spécifique plus ou moins durablement (Sedan,

123. Ibidem, p. 319-322, Articles arrestés d'un commun consentement par les pasteurs de la langue françoise de Mastricht et du pais d'Outremeuse, assemblés en classe à Mastricht, le 22 et suivants de Febvrier de 1634.

124. Ibidem, p. 324-326; [É. BouRLIER (éd.)], Livre synodal..., op. cit., vol. 1, p. 381, art. 3 du synode de Delft (avril 1634).

125. G.H.M. Posthumus Meyjes, H. Bots, J. Roelevink (éd.), Livres des actes..., op. cit., p. 334, art. 8 des actes de la classe de Limbourg (novembre 1634).

126. S. Des Marets, La Chandelle..., op. cit., n.p.; T. TRANQuille [G. WANDELman], La Chandelle esteinte..., op. cit., p. 199.

127. MAE, CP Hollande, vol. 16, $\mathrm{f}^{\circ} 574-680$, et vol. 17, pièce 1 . Voir aussi NA, inv. 1.01.02, vol. 3907 , vol. 4563 et vol. 4853 .

128. BU Leyde, BPL 297, $\mathrm{f}^{\circ} 24$.

129. NA, inv. 1.01.02, vol. 4562 (registre de délibérations secrètes), f $\mathrm{f}^{\circ} 256 \mathrm{v}-261 \mathrm{r}$.

130. BU Leyde, BPL 297, f 25-27, Conditions necessaires à la subsistence et liberté des Eglises Reformées à Maestricht et au pays de Limbourg en cas de vente ou engagement desdits lieux à S.M. Trèschretienne. Je ne ferai référence qu'aux numéros d'articles ci-dessous. 
mais aussi Metz, Orange ou le Béarn) ${ }^{131}$. Des Marets cherche à se prémunir, comme dans le mémoire déjà cité de juillet 1633 où il rappelait avoir été établi sous l'autorité des États-Généraux.

On voit les préoccupations du pasteur, qui se concentrent surtout sur les conditions juridiques et symboliques de la liberté d'exercice, rejetant par exemple la pratique catholique française d'employer le mot "prétendue» devant «réformée» pour désigner une Église (art. 2), ou encore s'inquiétant des obligations du régime de l'édit de Nantes et de sa jurisprudence sur les jours chômés (art. 3) et sur les processions (art. 4). Il s'agit aussi de formaliser l'accès des réformés aux offices municipaux ou aux métiers (art. 7 et 9) et de figer la situation des lieux d'exercice (art. 8 et 20). Dans une optique plus directement ecclésiastique, le nombre de pasteurs et leurs gages, ainsi que ceux des maîtres d'école, sont détaillés (art. 11-12). Un grand pragmatisme dû au particularisme du contexte transparaît dans d'autres passages. Ainsi, l'article 10 est centré sur le cas de Des Marets, qui a sans doute conscience que ses agissements antérieurs au cours des controverses liégeoises lui auraient valu des ennuis en France:

"Qu'à Maestricht les Ministres Regens du College, lecteurs des Eglises et $M^{\text {res }}$ d'Escholes par elles establis, seront pris par S. M. en sa particuliere protection sans estre en aucune sorte sujets ni justiciables, soit en demandant soit en deffendant de l'Evesque de Liege \& de ses officiers, mais purem[en]t \& simplem[en]t de S. M. \& des siens et que nommem[en]t $M^{\mathrm{e}}$ S. Des Marets, Ministre de l'Église Françoise à Maestricht ne pourra estre aucunem[en]t recerché pour aucune chose fait à luy improché, soit par luy faite, dicte, publiée \& imprimée où on voudroit pretendre que l'Evesque de Liege ou ses Magistrats Ministres, officiers, et Clergé auroient esté offensés directement ou indirectement».

Au-delà de son cas particulier, alors même que face au synode wallon le modèle français pouvait sembler être un horizon, le mémoire propose une réorganisation de la classe (désormais étendue aux Églises non francophones), à laquelle seraient confiées toutes les missions d'un synode provincial français (art. 13-17), mais sans lien avec eux. Au contraire, il est prévu:

"Que lesdictes Eglises \& leurs assemblées pourront entretenir quelque correspondance par lettres avec les Eglises \& assemblées classiques \& synodales des provinces unies pour demander leurs advis ès choses qui concerneroient la doctrine ou la discipline sans que pour lesdictes correspondances \& lettres, lesdictes Eglises puissent estre ou recerchées ou inquietées" (art. 26).

Les restrictions du pouvoir français apportées depuis la fin des années 1610 à la liberté des Églises de France de correspondre avec leurs sœurs à l'étranger, ainsi que la présence de commissaires royaux aux réunions, sont déterminantes, puisqu'il est explicitement précisé que les «officiers de S. M. qui resideront sur les lieux, [...] soubs quelque couleur ou pretexte que ce puisse estre ne pourront ni empescher lesdictes assemblées ni pretendre d'y assist[er]»

131. P. Chareyre, J. LÉONARd, Françoise Moreil, «Les Églises périphériques. Orange, Béarn, Metz, Sedan", in P. Chareyre, Hugues DAUssy (éd.), La France huguenote. Intégration institutionnelle d'une minorité religieuse (XVI ${ }^{e}-X V I I I^{e}$ siècle), Rennes, Presses universitaires de Rennes, à paraître. 
(art. 14). Le pragmatisme de Des Marets, qui rapproche son modèle ecclésial de celui en vigueur à Sedan alors indépendante, définit une identité disciplinaire et même confessionnelle particulière. Se perçoit-il encore comme un pasteur français ? Et comment le perçoit-on ? Dans le mémoire de décembre 1634, il est prévu d'imposer les "Confession de Foy \& discipline ecclesiastique des Eglises Reformées du Pays bas" (art. 18). Pourtant, dans le cadre de la controverse, c'est avant tout une identité française qu'il renvoie et qu'on lui renvoie, peutêtre afin de le faire passer pour un étranger aux yeux des Néerlandais, qui ne considèrent pas les Wallons comme tels ${ }^{132}$.

\section{RÉFÉRENCES FRANÇAISES, FIDÉLITÉS NÉERLANDAISES ET TRAHISON SEDANAISE}

Des Marets est présenté dans sa biographie autorisée de 1654 comme un pasteur "juris Belgici» dès le 3 octobre 1632, mais on a vu combien les conditions disciplinaires de son installation rendent cette assertion contestable, et peut-être reconstruite avec le temps ${ }^{133}$. Sa situation juridique, sans doute incertaine, ne préjuge en rien de son identité sociale et culturelle. En 1643 encore, il explique un conflit qui l'oppose à son collègue de Delft Samuel de Lescherpierre, sieur de La Rivière, par leur différence de caractère: «car je suis Picard \& luy Normand ${ }^{134}$. Dans ses controverses surtout, ce sont des références françaises qui sont mobilisées. Lorsqu'il fait œuvre de faussaire dans l'Abrégé de la voie de salut (1633) et prétend être un jésuite, c'est à l'histoire de France qu'il fait référence pour nier le caractère rebelle généralement attribué par les catholiques aux réformés:

«Les guerres de part \& d'autre ont beaucoup de miseres. Nous ne les faisons pas plus justement que les ennemis: mais pour les massacres, ils s'en pleignent bien plus que nous: les playes de la S. Berthelemy saignent encores en France; \& les cruautés du Duc d'Albe au Pays-bas ne seront jamais oubliées. Ils n'enseignent pas comme nous le meurtre des Roys, \& que le Pape les peut deposer, \& dispenser leurs sujets du serment de fidelité. [...] Si les Protestans ont pris par fois les armes pour maintenir leurs privileges \& defendre la liberté de leurs consciences, aussi avons-nous fait des sainctes ligues contre les souverains Magistrats, \& celle de France n'est que trop cogneuë» ${ }^{135}$.

Certes, cela peut aussi renvoyer aux Provinces-Unies, mais la question de l'assassinat des rois concerne principalement la mémoire encore présente d'Henri III et Henri IV tués en 1589 et $1610^{136}$. Dans le même état d'esprit,

132. W. FRIJHOFF, "Migrations religieuses dans les Provinces-Unies avant le second Refuge», Revue du Nord, 80-326/327, 1998, p. 573-598, notamment p. 576-577. Voir également Paul Lucien NĖVE, "Le statut juridique des réfugiés français huguenots; quelques remarques comparatives", in La condition juridique de l'étranger hier et aujourd'hui, Nimègue, Katholieke Universiteit Nijmegen, 1988, p. 223-245, p. 234.

133. Effigies..., op. cit., p. 147.

134. BU Leyde, BPL 297, f 79r, dans une lettre de Des Marets à Rivet, le 23 mai 1643.

135. [S. Des MARETS], Abregé..., op. cit., p. 23-24.

136. Monique CotTRet, Tuer le tyran? Le tyrannicide dans l'Europe moderne, Paris, Fayard, 2009. 
lorsqu'il se moque de Chokier dans sa Chandelle mise sous le boisseau, à cause de la qualité qu'il se donne de "vicaire de l'évêché» en l'absence de réel évêque, la comparaison qu'il trouve en fait "un tiltre aussi ridicule que ceux de la Ligue en France, qualifierent le duc de Mayenne Lieutenant general de l'Estat $\&$ Couronne de France ${ }^{137}$. Dans le même ouvrage, Des Marets convoque dans un de ses arguments «l'Eminentissime Cardinal de Richelieu, le plus judicieux esprit que nostre siecle ait veu ${ }^{138}$, ce qui lui vaut une série de réfutations en chaîne dans l'ouvrage du jésuite Wandelman. Pour Des Marets, le Premier ministre français sait séparer politique et religion et refuse l'emploi de la violence dans la sphère proprement confessionnelle, et il l'avance dès 1633 dans son Esprit du bourguemaistre Beckman ${ }^{139}$. Ses adversaires aussi se placent volontiers sur ce terrain, peut-être pour le contrer sur son identité française. Quand Wandelman veut défendre le culte des saints que Des Marets a qualifié de "stupidité», le meilleur moyen pour piéger le Picard est de prendre cet exemple: «S. Louys Roy de France, a esté veritablement un grand Sainct, \& est à très-bon droict honnoré de ceste qualité. Mais que nostre Samuel l'appelle Sainct. pag.59. c'est une stupidité» ${ }^{140}$. Politiquement, la fidélité naturelle de son adversaire ne semble donc guère faire de doute: "Voyez, comme vous pourrez respondre aux François, qui ont pour Patrons, S. Denys, S. Louys, \& autres, \& espargnez pour le moins, avec quelque respect, vostre Roy ${ }^{141}$.

Dans la lignée d'une stratégie développée en France, le jésuite s'attaque aussi à la vocation des réformateurs et des pasteurs, en s'appuyant sur l'article 31 de la confession de foi des Églises réformées de France, considérant sans doute que Des Marets en relève encore ${ }^{142}$, et avançant que sur les questions ecclésiastiques, il est en correspondance régulière avec Charles Drelincourt (1595-1669), né Sedanais et grand nom du protestantisme parisien prêchant à Charenton ${ }^{143}$. Ce renvoi à la confession de foi française (et non à la Confessio Belgica) est très fréquent, et fonde même le socle d'une réponse anonyme liégeoise à la Monachomachia de Des Marets. Sur cette feuille volante, imprimée d'un seul côté, l'auteur fait l'inventaire de trois passages du pasteur qui contreviennent aux articles 4 (définition des livres canoniques de la Bible), 5 (sur l'intangibilité des livres saints) et 24 (condamnant l'intercession des saints) de cette confession de foi, qui sont repris textuellement ${ }^{144}$.

137. S. Des Marets, La Chandelle..., op. cit., p. 86.

138. Ibidem, p. 198.

139. U. Capitaine (éd.), «Pièces relatives...", art. cit., p. 280.

140. T. Tranquille [G. WANDElman], La Chandelle esteinte..., op. cit., p. 79.

141. Ibidem, p. 121.

142. Ibidem, p. 85-87. Sur ce sujet: Bruno HüBSCH, Le ministère des prêtres et des pasteurs. Histoire d'une controverse entre catholiques et réformés français au début du XVII siècle, Lyon, RESEA-LARHRA, 2010.

143. T. TRANQUille [G. WANDElman], La Chandelle esteinte..., op. cit., p. 204-208.

144. Confession forcée de Saumuel Des Marets Ministre de Maestricht, en sa Monachomachie: Contre plusieurs Articles de sa Foy pretenduë; par ignorance de son propre Catechisme, \& par Esprit de contradiction, s.l. [Liège], s.n., s.d. [1633]; un exemplaire se trouve à la BU Liège, R177 E, f ${ }^{\circ} 70 \mathrm{v}$. 
Ces références forgent l'expérience si particulière de Samuel Des Marets. On peut tenter de définir quelles sont ses fidélités politiques et institutionnelles, à défaut de pouvoir réellement trancher la question de savoir s'il est toujours un pasteur français. Dans les pages qui précèdent, on l'a vu éviter le plus possible la soumission au synode wallon, mais solliciter les États-Généraux, et sans doute le prince d'Orange, qui ont garanti son installation en 1632 et dont il veut obtenir les moyens de sa consolidation. Sans aucun doute, on peut dire qu'il est au service des Provinces-Unies. Est-ce parce que ce sont des autorités lointaines qui lui permettent de conserver de l'autonomie? C'est possible, car on a vu comment il tente de limiter autant qu'il peut les conséquences d'une éventuelle intégration de Maastricht au royaume de France, qui ne lui poserait pas de problème de fidélité purement politique, puisqu'il est né sujet du roi Très-Chrétien et qu'il reste, on l'a bien vu, par bien des aspects un "pasteur français", mais qui modifierait l'articulation des liens entre l'autorité séculière et l'autorité ecclésiastique.

Terminons par une dernière clé d'interprétation de l'activité pastorale de Des Marets à Maastricht. Un événement décisif dans le monde de ses fidélités politiques se déroule très lentement, mais précisément entre 1633 et 1636 . Il s'agit de la conversion au catholicisme, secrète et déstabilisatrice, du duc Frédéric-Maurice de Bouillon, malgré le calvinisme militant de sa mère, Élisabeth de Nassau, première protectrice du pasteur. La correspondance entre Rivet et Des Marets est remplie d'allusions au sort du duc et à l'incertitude que ferait naître cette conversion dans des territoires menacés et fragiles comme Sedan et Maastricht. L'affaire débute lorsque Frédéric-Maurice projette d'épouser sa cousine catholique, Éléonore de Bergh (1613-1657), ce qui fait écrire au pasteur de Maastricht qu'«Il est capable d'ailleurs de faire mourir la bonne mère de regret» ${ }^{145}$. L'union est célébrée au début de l'année 1634, et Des Marets s'entretient dans l'illusion que l'épouse finira par se convertir, ou du moins que leurs enfants seront calvinistes. Or l'emprise de la duchesse sur la vie spirituelle de son époux est réelle, et le pasteur n'en a pas mesuré l'ampleur. En effet, dès le 27 octobre 1633, avant la cérémonie (catholique) de leur mariage, Frédéric-Maurice a abjuré le calvinisme au collège jésuite de Liège, en présence de dignitaires de Maastricht ${ }^{146}$. Des Marets semble n'en rien savoir (ou le feint-il ?) et continuer à espérer qu'Éléonore sera instruite, même s'il fait part à plusieurs reprises de son pessimisme à Rivet. Il dédicace sa Chandelle mise sous le boisseau au prince, en espérant ainsi le fortifier. En octobre 1635 cependant, la prise de conscience est définitive avec le baptême catholique du premier enfant du couple ${ }^{147}$. Ce n'est que le 5 juin 1636 que 
le duc communie publiquement à Maastricht ${ }^{148}$. À cette date, Des Marets est déjà parti pour Bois-le-Duc, et il faudra encore plusieurs semaines avant qu'Élisabeth de Nassau soit mise au courant.

C'est un parcours pastoral bien particulier et original que celui de Samuel Des Marets entre 1632 et 1636, mais un parcours qui montre bien des éléments en débat dans le monde réformé francophone, au-delà des frontières politiques. Né sujet du roi de France, formé comme un pasteur français et débutant sa carrière dans le système consistorial et synodal des Églises réformées de France, il s'engage à Sedan, puis à Maastricht, sur de véritables «fronts pionniers» de la Réforme ${ }^{149}$, et dans des systèmes disciplinaires différents qui cassent certains codes auxquels il était culturellement habitué. Entre disciplines des Églises de France et des Églises wallonnes, il choisit toujours l'option qui lui permet la plus grande liberté dans l'exercice de son ministère pastoral, tant pour attaquer les catholiques militants proches que pour consolider sa communauté, tout en développant une fidélité politique en apparence totale aux États-Généraux, mais sans renier le Roi Très-Chrétien.

À chacune des étapes que nous avons suivies, le contexte si particulier, à définir finement tant du point de vue géographique que chronologique, est déterminant. C'est bien cela qui permet à Des Marets, à l'échelle locale, de se forger une identité pastorale singulière et de donner à son Église des allures originales, dépendant à la fois d'éléments clairement identifiables comme français et d'influences néerlandaises, toujours dans une combinaison qui ne s'explique que par la position de Maastricht et de ses alentours, mais aussi par sa volonté personnelle d'établir son autonomie et sa réputation. Cette identité est combative, en partie déterminée par la controverse liégeoise, mais toujours avec des références plus générales. Assurément, ce cas particulier invite l'historien du protestantisme réformé au XVII ${ }^{\mathrm{e}}$ siècle à se pencher sur ces expériences francophones en marge et hors du royaume à l'époque de la guerre de Trente Ans, expériences riches en enseignements pour mieux comprendre les Églises qui sont généralement considérées comme "normales», et qui en tout cas servent de modèles dans l'historiographie.

Pour en revenir à Des Marets, cette période d'entre-deux s'achève brutalement avec la perte de repères qu'engendre la conversion du duc de Bouillon. Sans doute également déçu par l'échec en 1635 de la campagne franco-néerlandaise menée par Frédéric-Henri depuis Maastricht, notamment contre Louvain, mais aussi par la perte du Limbourg repris par les Espagnols, il quitte soudainement la ville en février 1636 pour répondre à la vocation qui

148. Pierre Congar, Jean LeCAillon, Jacques Rousseau, Sedan et le pays Sedanais: vingt siècles d'histoire, Paris, FERN, 1969, p. 302-305.

149. J'étends à Sedan l'expression employée pour Maastricht par J. vaN GENNIP, Controversen in Context..., op. cit., p. 255. 
lui est adressée par Bois-le-Duc. Il y devient ministre de l'Église francophone et professeur de l'École, sauvant la face en invoquant un accord l'engageant à accepter une chaire. Ce faisant, il s'enracine au service des Provinces-Unies et conforte (ou établit?) son statut de ministre «juris Belgici». Il meurt à Groningue le 18 mars 1673, après avoir été au service de l'université du lieu durant trente ans, en ayant très peu publié à nouveau en français, sans être revenu en France autrement que ponctuellement et pour des affaires familiales. Même lors de son passage à Paris dans ce cadre en 1659, c'est à l'ambassade néerlandaise qu'il prêche ${ }^{150}$. Pourtant, dans une attaque contre le clergé catholique pour condamner le Mars Gallicus de Jansénius, incluant une défense des idées politiques de Richelieu et de l'alliance franco-néerlandaise, il écrit en 1641 encore: «Le bon sang ne peut mentir; François je suis, \& mettant vos merites à leur prix, j'ai deu estre indigné à bon droit que ceux de ma Nation fussent si indignement traittés " ${ }^{151}$. Mais lorsqu'il meurt, on est au début d'une guerre de Hollande ayant définitivement tourné la page de l'alliance franco-néerlandaise qui a permis l'épanouissement de ses idées et de sa carrière.

$$
\begin{array}{r}
\text { Julien LÉONARD } \\
\text { Université de Lorraine - CRULH EA 3945 } \\
\text { ANR «LODOCAT» } \\
\text { Campus des Lettres et Sciences humaines } \\
23, \text { boulevard Albert I }{ }^{\text {er }} \\
\text { BP } 60446 \\
54001 \text { Nancy Cedex } \\
\text { julien.leonard@univ-lorraine.fr }
\end{array}
$$

150. S. Des MARets, Sermon sur le Pseaume V. vers. 8. Prononcé chez Monsieur l'Ambassadeur de Messieurs des Estats des Provinces-Unies le 3. Aoust 1659, Charenton, Perier, 1660.

151. S. Des MARETs, Eschantillon des maximes du clergé romain ès Provinces Unies; Représenté par le Chapitre onziésme de la seconde partie du livre intitulé Mars François, escrit contre la fustice des Armes $\mathcal{E}$ des Alliances du Roy Treschrestien; Avec un Discours sur icelluy, à Messieurs les Catholiques Romains de la Nation Françoise qui sont au service de ce pais, pour les justifier E esclaircir en ce sujet, Amsterdam, Janssen, 1641, p. 61. 


\section{Résumé / Abstract}

\section{Julien LÉONARD}

\section{Un pasteur français au service des Provinces-Unies. Le ministère de Samuel Des Marets} à Maastricht (1632-1636).

Né en France et exerçant le ministère pastoral réformé dans le royaume au cours de ses jeunes années, Samuel Des Marets (1599-1673) voit sa carrière prendre un virage précoce qui lui pose des problèmes d'identités confessionnelle et politique, dans la controverse, mais aussi dans son usage de la discipline ecclésiastique. Ministre et professeur de théologie dans la principauté indépendante de Sedan au milieu des années 1620, il passe sous la protection de sa régente, Élisabeth de Nassau, et de son fils, le prince Frédéric-Maurice, duc de Bouillon, lui-même proche de son oncle, le stathouder Frédéric-Henri. Établi par les États-Généraux et sur la recommandation d'André Rivet à Maastricht après la prise de la ville par les Provinces-Unies (1632), il exerce son ministère dans des conditions par certains aspects proches de celles de la France à la même époque (controverse, coexistence entre des communautés confessionnelles légales), mais marquées par des éléments irréductibles (co-souveraineté du prince-évêque de Liège, menace espagnole, intégration heurtée de son Église au synode). Tout cela le place dans une situation d'entre-deux dont il sait habilement jouer, usant alternativement des avantages de son statut de Français et de ceux de protégé des États-Généraux. Il le fait pour des raisons personnelles, mais aussi pour proposer un modèle pastoral de combat et consolider une Église qu'il a établie et veut protéger des attaques catholiques. À la fois de culture française et au service politique des Provinces-Unies, Samuel Des Marets développe, jusqu'à son départ pour Bois-le-Duc (1636), une position ambiguë, mais qui nous révèle bien des aspects de l'exercice du ministère pastoral dans une Église fraîchement établie sur un front confessionnel durant la guerre de Trente Ans.

MOTS-CLÉS: XVII ${ }^{\mathrm{e}}$ siècle, Maastricht, Liège, Provinces-Unies, Église réformée, controverse, Samuel Des Marets [ou Samuel Maresius]

\section{Julien LÉONARD \\ A French pastor in the service of the Dutch Republic. The ministry of Samuel Des Marets in Maastricht (1632-1636).}

Samuel Des Marets (1599-1673), born in France and practicing the reformed pastoral ministry in the kingdom during his early years, sees his career taking an early turn, causing him problems of confessional and political identities. It's obvious in the controversy, but also in his use of ecclesiastical discipline. Minister and professor of theology in the independent principality of Sedan in the mid-1620s, he passes under the protection of its regent, Elizabeth of Nassau, and her son, the prince Frederic-Maurice, Duke of Bouillon, himself in the entourage of his uncle, the Stadtholder Frederick Henry. Established by the States General and on the recommendation of André Rivet in Maastricht, after the taking of the city by the Dutch Republic (1632), he exercises his ministry under conditions which are in certain aspects close to those of France at the same time (controversy, coexistence between legal confessional communities), but marked by original elements (co-sovereignty of the prince-bishop of Liège, Spanish threat, difficulties of integration of his church into the Synod). All this places him in a situation of in-between, which he skilfully knows how to play, alternately using the advantages of his status of French and those of protégé of the States General. He does so for personal reasons, but also to propose the model of a combative pastor, and to consolidate a Church he has established and which he wants to protect from Catholic attacks. Samuel Des Marets maintains both his French culture and the political service of the Dutch Republic, until he leaves Maastricht for's-Hertogenbosch (1636). He develops an ambiguous position that reveals many aspects of the pastoral ministry in a newly established church on a confessional front during the Thirty Years' War.

KEYWORDS: $17^{\text {th }}$ century, Maastricht, Liège, Dutch Republic, Reformed Church, controversy, Samuel Des Marets [or Samuel Maresius] 